\title{
Targeting NMNAT1 to Axons and Synapses Transforms Its Neuroprotective Potency In Vivo
}

\author{
Elisabetta Babetto, ${ }^{1}$ Bogdan Beirowski, ${ }^{1}$ Lucie Janeckova, ${ }^{1}$ Rosalind Brown, ${ }^{2}$ Jonathan Gilley, ${ }^{1}$ Derek Thomson, ${ }^{2}$ \\ Richard R. Ribchester, ${ }^{2}$ and Michael P. Coleman ${ }^{1}$ \\ ${ }^{1}$ The Babraham Institute, Laboratory of Molecular Signalling, Cambridge CB22 3AT, United Kingdom, and ${ }^{2}$ Euan MacDonald Centre for MND Research, \\ Edinburgh EH8 9JZ, United Kingdom
}

\begin{abstract}
Axon and synapse degeneration are common components of many neurodegenerative diseases, and their rescue is essential for effective neuroprotection. The chimeric Wallerian degeneration slow protein ( $\mathrm{Wld}^{\mathrm{S}}$ ) protects axons dose dependently, but its mechanism is still elusive. We recently showed that Wld ${ }^{S}$ acts at a non-nuclear location and is present in axons. This and other recent reports support a model in which Wld ${ }^{S}$ protects by extranuclear redistribution of its nuclear NMNAT1 portion. However, it remains unclear whether cytoplasmic NMNAT1 acts locally in axons and synapses or at a non-nuclear site within cell bodies. The potency of axon protection by non-nuclear NMNAT1 relative to Wld ${ }^{\mathrm{S}}$ also needs to be established in vivo. Because the N-terminal portion of Wld ${ }^{\mathrm{S}}$ (N70) localized to axons, we hypothesized that it mediates the trafficking of the NMNAT1 portion. To test this, we substituted N70 with an axonal targeting peptide derived from amyloid precursor protein, and fused this to NMNAT1 with disrupted nuclear targeting. In transgenic mice, this transformed NMNAT1 from a molecule unable to inhibit Wallerian degeneration, even at high expression levels, into a protein more potent than Wld ${ }^{s}$, able to preserve injured axons for several weeks at undetectable expression levels. Preventing NMNAT1 axonal delivery abolished its protective effect. Axonally targeted NMNAT1 localized to vesicular structures, colocalizing with extranuclear Wld ${ }^{\mathrm{S}}$, and was cotransported at least partially with mitochondria. We conclude that axonal targeting of NMNAT activity is both necessary and sufficient to delay Wallerian degeneration, and that promoting axonal and synaptic delivery greatly enhances the effectiveness.
\end{abstract}

\section{Introduction}

Axonal degeneration is a primary or contributory component of many neurodegenerative diseases and a promising therapeutic target (Raff et al., 2002; Saxena and Caroni, 2007). Studies of the mutant mouse Wld $^{\mathrm{S}}$ (Wallerian degeneration slow) (Lunn et al., 1989) established axonal degeneration as a tightly regulated process. In this strain, the chimeric $\mathrm{Wld}^{\mathrm{S}}$ protein delays the progressive degradation of experimentally transected nerves (Wallerian degeneration) (Waller, 1850), preserving axons and synapses in a nonlinear, dose-dependent fashion (Mack et al., 2001). Importantly, Wld ${ }^{\mathrm{S}}$ ameliorates axonopathy in models of various neurodegenerative conditions, such as progressive motor neuronopathy, CharcotMarie-Tooth disease, Parkinson's disease, and glaucoma (Ferri et al., 2003; Samsam et al., 2003; Sajadi et al., 2004; Howell et al., 2007; Beirowski et al., 2008), opening new avenues for therapeutic approaches.

\footnotetext{
Received March 8, 2010; revised May 28, 2010; accepted Aug. 2, 2010.

This work was supported by the Biotechnology and Biological Sciences Research Council, the Medical Research Council, and the Alzheimer's Research Trust (ART/PG2005/2). R.R.R. was supported by Motor Neurone Disease Association and MND Scotland. We thank Prof. Yasuhiro Watanabe for providing FLAG-tagged SOD1 mouse brains, Prof. Roger Tsien for mCherry, Dr. Michele Di Stefano for advice on NMNAT activity assay, Dr. Laura Conforti for helpful discussion, and the staff of the Babraham Institute Facilities, in particular Dr. Simon Walker and Dr. Anne Segonds-Pichon for advice on imaging and statistics, respectively.

Correspondence should be addressed to Dr. Michael P. Coleman, Laboratory of Molecular Signalling, The Babraham Institute, Babraham Research Campus, Babraham, Cambridge CB22 3AT, United Kingdom. E-mail: michael. coleman@bbsrc.ac.uk.

DOI:10.1523/JNEUROSCI.1189-10.2010

Copyright $\odot 2010$ the authors $\quad 0270-6474 / 10 / 3013291-14 \$ 15.00 / 0$
}

The mechanism of $\mathrm{Wld}^{\mathrm{S}}$ protection remains largely elusive at the molecular level. Wld ${ }^{\mathrm{S}}$ arose from a de novo triplication, which links the N-terminal 70 aa of the ubiquitination factor Ube $4 b$ (N70) to the nuclear $\mathrm{NAD}^{+}$-synthesizing enzyme nicotinamide mononucleotide adenylyltransferase (NMNAT1), via a unique 18 aa sequence (Wld18) (Conforti et al., 2000). Despite its abundance in the nucleus, we recently detected Wld ${ }^{\mathrm{S}}$ in axons, where it accumulates after nerve constriction (Beirowski et al., 2009). Since axonally transported proteins typically accumulate at constriction sites (Cavalli et al., 2005), Wld ${ }^{S}$ may be transported, either directly or by associating with vesicles or organelles. Moreover, redistribution of $\mathrm{Wld}^{\mathrm{S}}$ to cytoplasm strikingly enhanced axonal and synaptic protection (Beirowski et al., 2009), possibly by increasing the delivery to axons and synapses where $\mathrm{Wld}^{\mathrm{S}}$ may function locally.

Further support for this model comes from studies of the NMNAT1 portion of Wld ${ }^{\mathrm{s}}$. The intrinsic catalytic activity of $\mathrm{Wld}^{\mathrm{S}}$ is required for the phenotype in vitro and in vivo (Araki et al., 2004; Jia et al., 2007; Avery et al., 2009; Conforti et al., 2009). Nuclear NMNAT1 is not sufficient to confer axon protection in mice and has only a weak effect in Drosophila and in primary neuronal culture relative to $\mathrm{Wld}^{\mathrm{S}}$ (Conforti et al., 2007; Avery et al., 2009; Sasaki et al., 2009b; Yahata et al., 2009). If NMNAT1 is shifted outside the nucleus (cytNMNAT1), the protection in culture is enhanced and cytNMNAT1 can also protect axons in vivo when overexpressed at least 15-fold more than Wld ${ }^{\mathrm{S}}$ (Sasaki et al., 2009b). However, it remains unclear whether near-physiological levels of 
NMNAT1 are sufficient to protect injured axons in mice, and whether the critical site is axonal or somatic.

We report here that targeting NMNAT1 to axons greatly enhances its protective potential in vivo. We show for the first time that even a marginal increase in NMNAT level becomes robustly protective as long as NMNAT1 is delivered to axons, and that preventing axonal entry abolishes this effect. Finally we find that axonally targeted NMNAT1 colocalizes with extranuclear Wld ${ }^{\mathrm{S}}$ and it is transported in coordinated movement with mitochondria.

\section{Materials and Methods}

Plasmids and generation of transgenic mice. An NMNAT1 construct with disrupted nuclear targeting, termed $\triangle$ NLS NMNAT1, was PCR amplified from the previously reported $\Delta \mathrm{NLS}$ Wld ${ }^{\mathrm{S}}$ construct, carrying the R213A and R215A mutations (Beirowski et al., 2009). The FLAG reverse primer (BamHI site underlined, mutated stop codon in bold, FLAG tag italicized: 5'-CGCGGATCCTCACTTGTCATCGTCGTCCTTGTAATCTCCCAGAGTGGAATGGTTGTGCTTGGC-3') (Wilbrey et al., 2008) was used together with the following forward primers ( $5^{\prime}$ HindIII cloning tag underlined, start codon in bold, axonal targeting sequence italicized).

For $\triangle$ NLS NMNAT1-FLAG: 5' -TAGATCCCAAGCTTAACTTCTCCCCATGGACTCAT-3' (Conforti et al., 2007).

For Exon7 SMN- $\triangle$ NLS NMNAT1-FLAG: 5'-ATCCCAAGCTTAACTTCTCCCCATGGGTTTCAGACAAAATCAAAAAGAAGGAAGGTGCTCACATTCCTTAAATGACTCATCCAAGAAG-3'.

For GAP43 MEM- $\triangle$ NLS NMNAT1-FLAG: 5'-ATCCCAAGCTTAACTTCTCCCCATGCTGTGCTGTATGAGAAGAACCAAACAGGTTGAAAAGAATGATGAGGACCAAAAGATCGACTCATCCAAGAAG-3'.

For AICD- $\triangle$ NLS NMNAT1-FLAG (subsequently named Ax-NMNAT1): 5'-ATCCCAAGCTTAACTTCTCCCCATGGGATATGAGAATCCAACTTACAAGTTCTTTGAGCAAATGCAGAAC GACTCATCCAAGAAG-3'.

NMNAT1-FLAG cDNA was prepared as for $\triangle$ NLS NMNAT1-FLAG using Wld ${ }^{\mathrm{S}} \mathrm{cDNA}$ as template.

FLAG-tagged constructs expressing the first N70 aa of Ube $4 \mathrm{~b}$ without (N70-FLAG) and with (N70-Wld18-FLAG) the 18 unique amino acids (Wld18) were amplified from Wld ${ }^{\mathrm{S}} \mathrm{cDNA}$ contained in $\mathrm{pH} \beta \mathrm{APr}-1$ vector (Mack et al., 2001). Act F (5'-ACTTCGGCTCACAGCGCG-3'), annealing within the $\beta$-actin promoter, was used as forward primer and the following sequences were used for reverse primers (BamHI cloning site underlined, stop codon in bold, FLAG tag italicized):

For N70-FLAG: 5'-CGCGGATCCTCACTTGTCATCGTCGTCCTTGTAATCTGCTGCACCTATGGGGG-3'

For N70-Wld18-FLAG: 5'-CGCGGATCCTCACTTGTCATCGTCGTCCTTGTAATCGGGGAGAGTTGGTGGTGT-3'.

The FLAG-tagged construct expressing the 18 unique aa followed by the full-length NMNAT1 cDNA (18-NMNAT1-FLAG) was amplified from the same template using the following forward primer ( $5^{\prime}$ HindIII cloning tag underlined, start codon in bold) and Wld ${ }^{\mathrm{S}}$-FLAG reverse (Wilbrey et al., 2008): 5'-GCCGAAGCTTAAGAAAGCGATGGACAACATCGCTGTC-

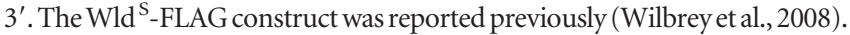

All the PCR products were double digested with BamHI and HindIII restriction enzymes and cloned into $\mathrm{pH} \beta \mathrm{APr}-1$ vector downstream of the $\beta$-actin promoter for expression in neurons and other cell types as described by Mack et al. (2001). Ax-NMNAT1-mCherry was produced by PCR amplification using BamHI- and HindIII-tagged primers and subcloned in-frame to the mCherry sequence into pcDNA3 vector. The sequence of each construct was then verified. For transfection, plasmids were prepared using the EndoFree Plasmid Maxi-kit (Qiagen).

The Ax-NMNAT1 construct within $\mathrm{pH} \beta \mathrm{APr}-1$ was digested with EcoRI/ NdeI and the resulting $5.7 \mathrm{kbp}$ linear DNA was used for pronuclear microinjection into an F1 C57BL/CBA strain by the in-house Gene Targeting Facility of the Babraham Institute. Founders were crossed to homozygous YFP-H mice (Feng et al., 2000) and their progeny genotyped by Southern blotting. For this study, we also used double-heterozygous native Wld $\mathrm{s}$ / YFP-H mice, triple-heterozygous tg-Wld ${ }^{\mathrm{S}} / \mathrm{Wld}^{\mathrm{S}} / \mathrm{YFP}-\mathrm{H}$ mice, homozygous natural Wld $^{S}$ mice, NMNAT1-overexpressing/YFP-H mice (line 7104) (Conforti et al., 2007), double-hemizygous $\Delta$ NLS Wld ${ }^{\mathrm{S}} /$ YFP-H mice (line 2 and 3) (Beirowski et al., 2009), and double-hemizygous $\Delta$ N16 Wld ${ }^{\mathrm{S}} / \mathrm{YFP}-\mathrm{H}$ mice (line 1) (Conforti et al., 2009). Triple-heterozygous $\operatorname{tg}^{-W l d}{ }^{\mathrm{S}} / \mathrm{Wld}^{\mathrm{S}} /$ YFP-H mice express levels of Wld ${ }^{\mathrm{S}}$ protein similar to that in homozygous natural Wld ${ }^{\mathrm{S}}$ mice and display a similarly retarded time course of axon degeneration (Beirowski et al., 2005).

All animal work was performed in accordance with the Animals (Scientific Procedures) Act (1986) under Project Licenses PPL 80/1778 and PPL 80/2254.

Genotyping. For mouse genotyping by Southern blotting, genomic DNA extracts were digested by BamHI and HindIII (Invitrogen) at $37^{\circ} \mathrm{C}$ overnight, and run on $0.8 \%$ agarose gels in TBE. The gels were denatured in $0.4 \mathrm{M} \mathrm{NaOH}$ with two changes at $30 \mathrm{~min}$ intervals. The gel was Southern blotted overnight onto Hybond XL (GE Healthcare) in $0.4 \mathrm{M} \mathrm{NaOH}$, and hybridized with a probe of radioactive Wld ${ }^{\mathrm{S}}$ cDNA. Posthybridization washes were performed at a stringency of $0.1 \times$ SSC, $0.1 \%$ SDS. Radioactive filters were exposed to $\mathrm{x}$-ray film for $24 \mathrm{~h}$ or longer at $-80^{\circ} \mathrm{C}$.

Cell culture. Culture and transfection of hippocampal neurons were described previously (Wilbrey et al., 2008) and dorsal root ganglion (DRG) neurons were processed in a similar way. In brief, dissociated neurons from E14.5-E16.5 embryos were plated on coated glass coverslips or IBIDI $\mu$-dishes, and transfected at DIV 3-5. Neurons were cut with a scalpel to test axonal preservation $24 \mathrm{~h}$ after transfection or fixed with $4 \%$ paraformaldehyde (PFA) in $0.1 \mathrm{M}$ PBS 20-48 h later for immunofluorescence and high-resolution confocal imaging. DRG explants from E14.5-E16.5 embryos were dissected and plated as described by Conforti et al. (2007). Aphidicolin ( $2 \mu \mathrm{M})$ was added to dissociated and explant DRG cultures to reduce the number of non-neuronal cells. Neurites were axotomized with a scalpel at DIV 7 and phase-contrast pictures of the same field were taken immediately $(0 \mathrm{~d})$ and 1,3 , and $6 \mathrm{~d}$ after cutting. An Olympus IX81 microscope coupled to a PC running SIS imaging software was used for image acquisition. A second cut was performed at the same location $3 \mathrm{~d}$ after the first axotomy to avoid regeneration and DRGs were rinsed with fresh medium. Explants were collected at DIV 13 for Western blot analysis.

Treatments with microtubule destabilizing agent. Vincristine (Sigma) and nocodazole (Calbiochem) were diluted in DMSO and added to the cultures at the final concentrations of $0.04 \mu \mathrm{M}$, and 5 or $20 \mu \mathrm{g} / \mathrm{ml}$, respectively, at the indicated times (see Fig. 7). DMSO was used for control cultures. Medium with fresh drugs was replaced every $24 \mathrm{~h}$.

Assessment of in vivo axonal preservation. We used expression of the YFP-H transgene for longitudinal imaging of YFP-labeled axons in sciatic and tibial nerve, an established method for morphological assessment of axonal preservation (Feng et al., 2000; Beirowski et al., 2004; Beirowski et al., 2005; Conforti et al., 2009). Mice were anesthetized with isoflurane (Abbot Animal Health) and subcutaneous injection of $2.5 \mu \mathrm{g}$ of buprenorphine hydrochloride (Vetergesic, Alstoe Lt. Animal Heath), and unilateral sciatic nerve lesion was performed as described by Beirowski et al. (2009); the contralateral side served as control. A $5 \mathrm{~mm}$ segment of sciatic nerve was removed to prevent regeneration complicating the analysis of the distal stump at longer lesion durations (14-35 d). Seven, fourteen, and thirtyfive days after surgery, mice were humanely killed and $\sim 1.5-\mathrm{cm}$-long nerve distal stumps removed. The lesion site was inspected to confirm that the proximal and distal stumps had remained separated. Nerves were immersion-fixed in $4 \%$ PFA and $0.1 \mathrm{M}$ PBS and processed for imaging on a Zeiss LSM 510 Meta confocal system as previously described (Beirowski et al., 2004). Confocal $z$-stack series from longitudinally embedded nerve were taken using a $20 \times$ magnification objective, and $z$-projections were generated for final presentation using algorithms from Zeiss LSM Software Release 3.2. We quantified unfragmented YFP-positive axons in the distal tibial nerve as a percentage of the mean number of YFP-positive axons in uninjured preparation.

Assessment of in vitro axonal preservation. For transection experiments on DRG explant cultures (see Fig. 4), phase-contrast images (20× magnification) of axotomized neurites were taken at $0,1,3$, and $6 \mathrm{~d}$. Brightness and contrast were adjusted for an entire $0.3 \mathrm{~mm} \times 0.3 \mathrm{~mm}$ square from each image using Adobe Photoshop to obtain similar background intensities. Images were further processed using NIH ImageJ software similar to the method described by Sasaki et al. (2009a). Accordingly, images were binarized so that axons appear black. The degree of axonal 
continuity was scored using the Particle Analyzer tool with size (in square pixels) set at 100 to infinity. This algorithm measures the number of black pixels in continuous axons and excludes axons with high degree of fragmentation. We normalized it for the total number for black pixels (total axonal area) in the field to obtain a protection index (PI) value. Typically an image of intact axons has a PI value around 1 and an image of fragmented axons has a PI value around 0.5. A PI around 0 occurs when axons detach from the dish (such fields where excluded from the quantification) or when only debris remains that is smaller than the minimum set size (100 square pixels). Results from C57BL/6 embryos and AxNMNAT1-negative embryo littermates were grouped together as wildtype (WT) control. For each genotype, images from 3-10 dishes were quantified (2-3 fields/dish). DRG explant cultures in presence of microtubule destabilizing agents (see Fig. 7) were cut and imaged in the same way. Axonal protection of dissociated DRG neurons was tested by cutting single neurons that coexpressed EGFP and Ax-NMNAT1-mCherry. Neurons were imaged with an Olympus IX81 microscope, and only the ones coexpressing green and red fluorescence were selected to be axotomized. The percentage of axons that did not develop extensive varicosities or fragmentation $48 \mathrm{~h}$ after cut was quantified $( \pm S D)$, in presence or absence of microtubule-destabilizing agents (see Fig. 7) (10-20 neurons/ condition, 2-4 dishes tested).

NMNAT enzyme activity assay. Brains were divided in half sagittally, snap frozen in liquid nitrogen, and kept at $-80^{\circ} \mathrm{C}$. One hemisphere was used for NMNAT activity assay and the other was used for Western blot analysis. NMNAT assay was performed as described previously (Mack et al., 2001) with minor modifications. Tissue was Ultra-Turrax homogenized in 5 volumes of ice-cold buffer [50 mM HEPES, pH 7.4, $0.5 \mathrm{~mm}$ EDTA, $1 \mathrm{~mm} \mathrm{MgCl}_{2}, 1 \mathrm{~mm}$ DTT, and protease inhibitor (Mini-protean EDTA-free, Roche) ]. NMNAT activity assay was performed at $37^{\circ} \mathrm{C}$ in a $0.15 \mathrm{ml}$ reaction mixture containing $50 \mathrm{~mm}$ Tris- $\mathrm{HCl}, \mathrm{pH} 7.5,5 \mathrm{~mm}$ nicotinamide mononucleotide (NMN), $3 \mathrm{~mm} \mathrm{ATP,} 20 \mathrm{~mm} \mathrm{MgCl}_{2}, 20 \mathrm{~mm}$ $\mathrm{NaF}$, and an appropriate aliquot of brain homogenate. The reaction was started by adding $5 \mathrm{~mm}$ NMN and stopped by the addition of a halfvolume of ice-cold $1.2 \mathrm{M} \mathrm{HClO}_{4}$. After $10 \mathrm{~min}$ at $0^{\circ} \mathrm{C}$, the mixture was centrifuged and $100 \mu \mathrm{l}$ of supernatant was neutralized by the addition of $26 \mu$ lof $0.8 \mathrm{M} \mathrm{K}_{2} \mathrm{CO}_{3}$. NMNAT activity was calculated by reverse-phase HPLC identification ( $\mathrm{C} 18$ column) and quantification of the product $\left(\mathrm{NAD}^{+}\right)$. One unit of enzyme was defined as the amount capable of producing $1 \mu \mathrm{mol}$ of $\mathrm{NAD}^{+}$per minute at $37^{\circ} \mathrm{C}$. Specific NMNAT activity was obtained by normalization with protein content calculated by Bradford assay (Bio-Rad).

Assessment of in vivo preservation of neuromuscular junctions. Mice were killed by cervical dislocation and previous section of the sciatic nerve was verified by reexposing the wound in the thigh. Tibial nerveflexor digitorum brevis (FDB) and lumbrical preparations were dissected in Babraham and bathed in oxygenated mammalian physiological saline ( $137 \mathrm{~mm} \mathrm{NaCl}, 5 \mathrm{~mm} \mathrm{KCl}, 2 \mathrm{~mm} \mathrm{CaCl}, 1 \mathrm{~mm} \mathrm{MgCl} 2,5.6 \mathrm{~mm}$ glucose, and 5 mм HEPES, pH 7.2-7.4, equilibrated with 100\% oxygen). In some experiments, preparations were dissected then couriered in cold $\left(4^{\circ} \mathrm{C}\right)$ physiological saline to Edinburgh, where electrophysiological recordings were made later the same day as described by Mack et al. (2001). Miniature endplate potentials (MEPPs) and evoked synaptic response (EPPs) to tibial nerve stimulation were recorded and quantified in FDB muscles from $6 \mathrm{~d}$ lesioned age-matched Wld ${ }^{\mathrm{S}}$ homozygotes and $3 \mathrm{Ax}$-NMNAT1 hemizygotes from line 2 for each of these tests. Contralateral muscles were used as uncut controls. For morphological quantification of neuromuscular junctions (NMJs), preparations of FDB and lumbrical muscles from age-matched, $6 \mathrm{~d}$ lesioned Ax-NMNAT1, Wld ${ }^{\mathrm{S}}, \Delta \mathrm{NLS} \mathrm{Wld}^{\mathrm{S}}$, NMNAT1, and WT mice were retained in Babraham, and pinned to a Sylgard-lined dish. Recycling synaptic vesicles of motor nerve terminals were stained using AM1-44 (8 $\mu \mathrm{M})$ (Biotium) and acetylcholine receptors were stained with tetramethylrhodamine isothiocyanate conjugates of $\alpha$-bungarotoxin (TRITC- $\alpha$-BTX) $(5 \mu \mathrm{g} / \mathrm{ml})$ (Biotium) in depolarizing saline $[50 \mathrm{~mm} \mathrm{KCl} / 75 \mathrm{~mm} \mathrm{NaCl}$ substitution, as described by Ribchester et al. (1994)]. AM1-44 is a fixable form of styryl-dye FM1-43, a widely used vital label of NMJs, and indicates functional synaptic transmission. Muscles were fixed in 4\% PFA, $0.1 \mathrm{~m}$ PBS for $20 \mathrm{~min}$ and mounted on conventional glass slides in Vectashield mounting medium for subse- quent analysis. For endplate occupancy, we assessed alignment of the presynaptic AM1-44 vital marker and the postsynaptic TRITC- $\alpha$-BTX staining using an IX81 Olympus fluorescence microscope. Muscle preparations were imaged using a Zeiss LSM 510 Meta confocal system in Multi-track mode to avoid fluorescence bleed-through, and $z$-series were merged using algorithms from Zeiss LSM Software Release 3.2.

Immunohistochemistry and immunocytochemistry. For immunofluorescence detection of axonally targeted NMNAT1 in brains, Ax-NMNAT1 mice were intracardially perfused with $4 \%$ PFA in $0.1 \mathrm{M}$ PBS and brains were postfixed for $24 \mathrm{~h}$, cryopreserved for $3 \mathrm{~d}$, embedded in OCT medium, and subsequently sectioned using a Leica cryostat. Perfused brains of transgenic mice expressing FLAG-tagged SOD1 (kind gift from Prof. Yasuhiro Watanabe, Tottori University, Tottori, Japan) (Watanabe et al., 2005) were cryosectioned and processed as positive controls. Sections $(20 \mu \mathrm{m})$ were mounted onto SuperFrost Plus glass slides (VWR) and incubated overnight in citrate buffer, $\mathrm{pH} 6.0$, at $50^{\circ} \mathrm{C}$ for antigen retrieval. After permeabilization with $0.1 \%$ Triton $\mathrm{X}-100$ plus $0.05 \mathrm{M} \mathrm{NH}_{4} \mathrm{Cl}$ in $0.05 \mathrm{M}$ TBS for $10 \mathrm{~min}$, the sections were rinsed in fresh TBS, immunoblocked with $5 \%$ bovine serum albumin (Sigma) in TBS for $1 \mathrm{~h}$, and incubated overnight at $4^{\circ} \mathrm{C}$ in primary antibody solution (Sigma F1804 mouse anti-FLAG antibody, 1:500 in 0.8\% bovine serum albumin in TBS). After extensive washes, the secondary antibody solution (Alexa568-goat anti-mouse, 1:200 in TBS) was applied for $1 \mathrm{~h}$ at room temperature and slices were rinsed in TBS and $\mathrm{dH}_{2} \mathrm{O}$.

For immunofluorescence of transfected hippocampal neurons, cells were fixed in 4\% PFA, 0.1 M PBS for 10 min, permeabilized with $1 \%$ Triton X-100 for $10 \mathrm{~min}$, blocked [5\% NGS (Sigma) in PBS, $1 \mathrm{~h}$ ], and immunostained with mouse anti-FLAG antibody (1:2000) (Sigma F3165) overnight followed by $1 \mathrm{~h}$ incubation with secondary Alexa568-goat anti-rabbit antibody (1:200) (Invitrogen), both diluted in 5\% NGS in PBS. In hippocampal cultures, dendrites were counterstained with chicken anti-MAP-2 antibody $(1: 30,000)(\mathrm{AbCam})$ and secondary Alexa647-goat anti-chicken antibody (Invitrogen). Proximal axons were stained with rabbit anti-Ankyrin G antibody (1:400) (Santa Cruz Biotechnology) and secondary Alexa488-goat anti-rabbit antibody (Invitrogen).

Cryosections and cell culture samples were mounted in Vectashield mounting medium containing DAPI for nuclear counterstaining (Vector Laboratories) and imaged using the Zeiss LSM 510 Meta Confocal system in Multi-track mode to avoid fluorescence bleed-through. $Z$-series were merged using projection algorithms from Zeiss LSM Software Release 3.2.

Western blotting and subcellular fractionation. Western blotting of total brain homogenates (see Fig. 2) was performed as described by Conforti et al. (2007) with minor modifications. Brains were homogenized in 5 volumes of RIPA buffer, high-speed supernatant was further centrifuged at $2000 \times g$ for $5 \mathrm{~min}$, and concentrated brain homogenate was loaded for SDS-PAGE and blotted to PVDF membranes. After overnight blocking, the Western blot was probed with anti-NMNAT1 antibody 183 (1:250) (Conforti et al., 2000) or mouse anti-FLAG antibody (1:1000) (Sigma F1804) for $3 \mathrm{~h}$ at room temperature. This was followed by incubation with the appropriate IgG-HRP-conjugated secondary antibodies. Mouse monoclonal anti- $\beta$-actin (Abcam) was used as loading control. Cell bodies and neurites of $\sim 30$ DRGs were harvested, resuspended in $150 \mathrm{~mm}$ $\mathrm{NaCl}, 50 \mathrm{~mm}$ Tris/ $\mathrm{HCl}$, and 10\% SDS, pH 8.0, boiled, and loaded in one well of SDS-polyacrylamide gel for immunoblotting as above. Brain nuclear and postnuclear fractions (see Fig. 5) were obtained as described by Beirowski et al. (2009). More extensive subcellular fractionation (see Fig. 8 ) was performed as follows. Brains were homogenized in 5 volumes of buffer (300 mм sucrose, 10 mm HEPES, 5 mm EDTA, protease inhibitor, $\mathrm{pH}$ 7.4) and centrifuged at increasing speed as described by Beirowski et al. (2009) to obtain the nuclear, postnuclear, and mitochondria-enriched fractions. All pellets were resuspended in homogenization buffer containing $0.5 \mathrm{~mm} \mathrm{NaCl}$. Vesicle fractions were obtained from the supernatant of the mitochondria-enriched fraction as described previously (Morfini et al., 2001; Lazarov et al., 2005): V0 [40,000 $\times g$ (max) for 40 $\min$ at $\left.4^{\circ} \mathrm{C}\right], \mathrm{V} 1\left[120,000 \times g(\max )\right.$ for $40 \min$ at $\left.4^{\circ} \mathrm{C}\right], \mathrm{V} 2[260,000 \times g$ (max) for $2 \mathrm{~h}$ at $\left.4^{\circ} \mathrm{C}\right]$. The supernatant of the last spin yielded the cytosol. Purity was validated by probing with the following antibodies: mouse anti-calnexin, mouse anti-adaptin $\gamma$ (both from BD Biosciences), rabbit anti-Sp1 (Santa Cruz), mouse anti-p38 synaptophysin (SNPH) (DAKO), and rabbit anti-prohibitin (Abcam), and (variant) Wld ${ }^{\mathrm{s}}$ was detected by 
A
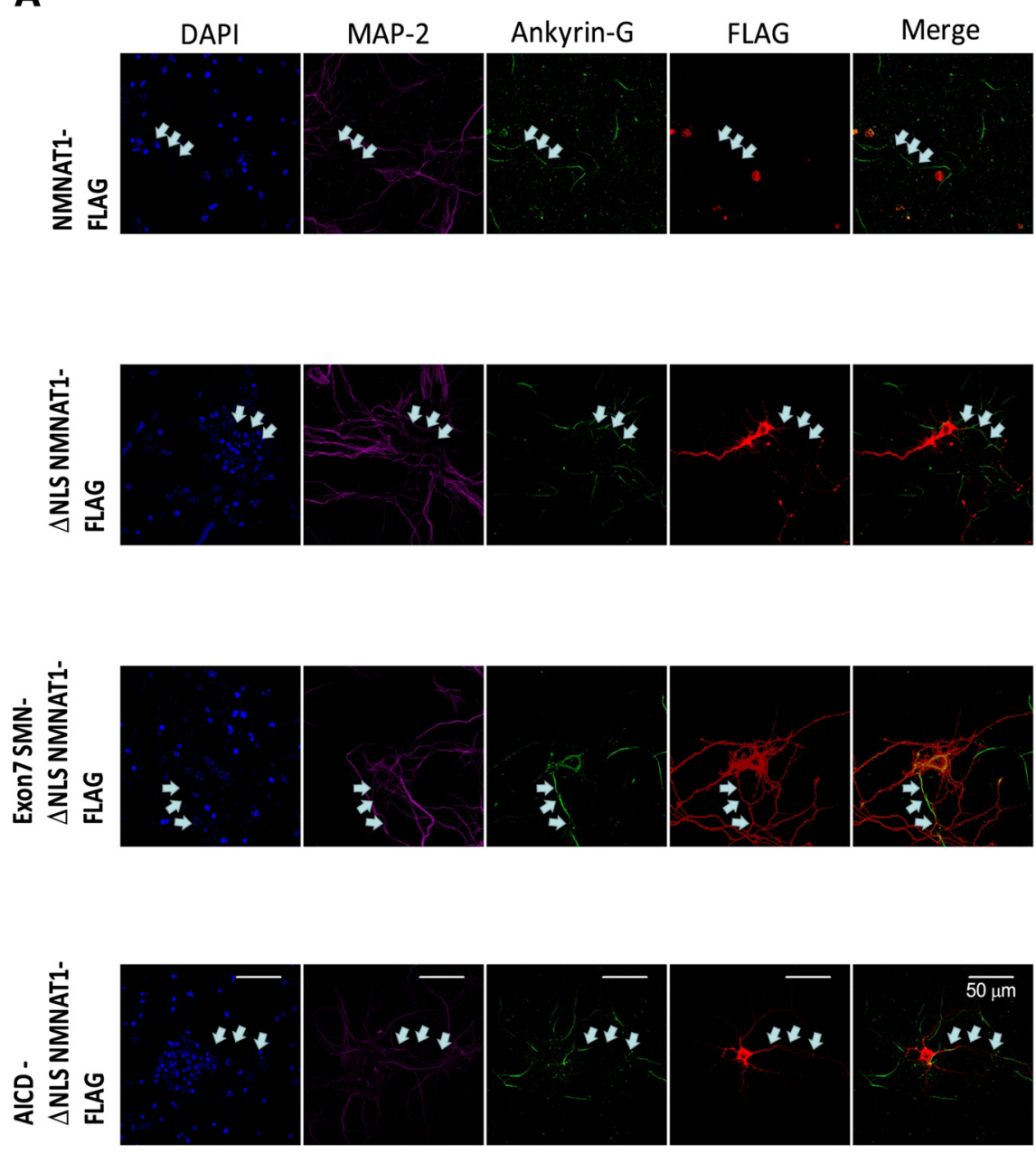

B

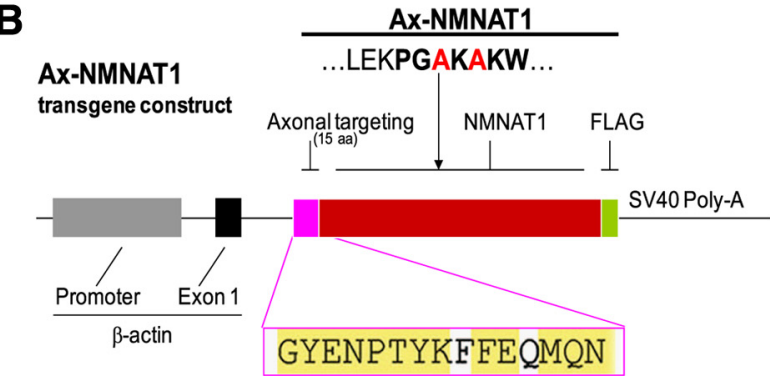

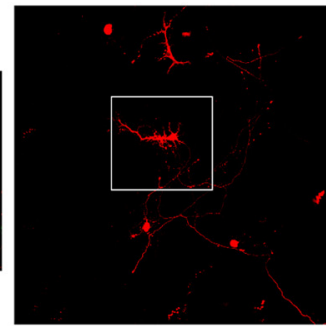
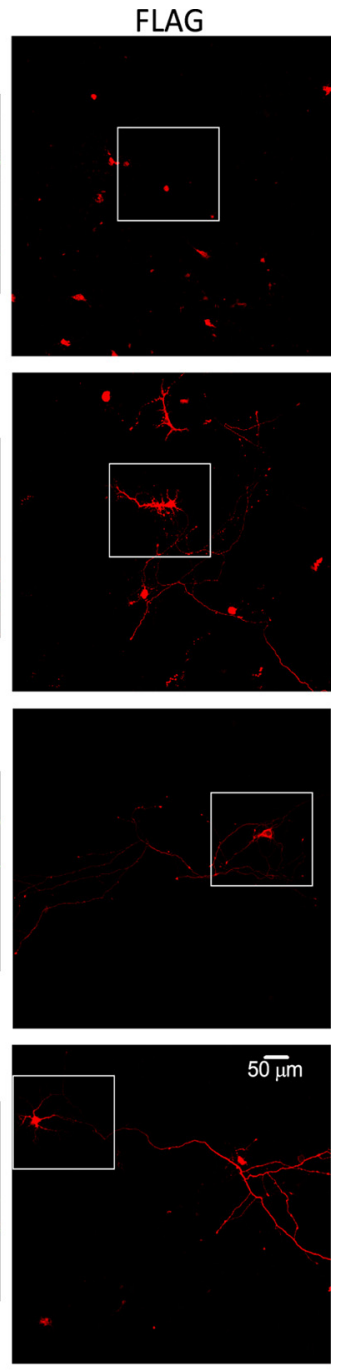

Figure 1. Confocal z-projections showing the targeting of NMNAT1 to axons. A, Immunostained hippocampal neurons transfected with FLAG-tagged native NMNAT1 (NMNAT1-FLAG), FLAGtagged NMNAT1 with disrupted nuclear localization ( $\triangle$ NLS NMNAT1-FLAG), and FLAG-tagged $\triangle N L S$ NMNAT1 N-terminally fused to a peptide from exon 7 of SMN protein (Exon7 SMN- $\Delta N L S$ NMNAT1-FLAG) or to a peptide from the AICD of APP (AICD- $\triangle$ NLS NMNAT1-FLAG). Anti-FLAG immunocytochemistry labeled the overexpressed NMNAT1 variants (red). On the right, $20 \times$ images show that AICD- $\triangle$ NLS NMNAT1-FLAG redistributes to distal axons most efficiently. (ell body insets are shown at $63 \times$ magnification on the left. Anti-ankyrin G identified proximal axons (green), and anti-MAP-2 marked dendrites (pink); nuclei were counterstained with DAPI (blue). Superimposed images of overexpressed NMNAT1 variants and ankyrin $G$ are shown in the merge panel. Arrows point to axons. $\boldsymbol{B}$, The AICD- $\triangle$ NLS NMNAT1-FLAG construct was named Ax-NMNAT1 (axonally targeted NMNAT1) and selected for the generation of transgenic mice. In the N-terminal axonal targeting sequence, evolutionarily conserved amino acids are highlighted in yellow.

antibody Wld18 (Samsam et al., 2003), all followed by the appropriate secondary IgG-HRP-conjugated antibody. Protein concentration was measured by Bradford assay (Bio-Rad) and similar amount of protein from all fractions was used for immunoblots.

Time-lapse imaging. Transfected dissociated DRG and hippocampal neurons were imaged as described previously (Gilley and Coleman, 2010) within $24 \mathrm{~h}$ after transfection, and immediately after treatment with MitoTracker Green FM (Invitrogen), as per manufacturer protocol. Wide-field epifluorescence images were captured at $1 \mathrm{~Hz}$. After acquisition dishes were moved to a Zeiss LSM510 confocal and stacks acquired.
Statistical analysis. Data are presented as mean $\pm \mathrm{SD}$. Student $t$ test was performed for statistical analysis: group comparison was considered not statistically significant (NS) if $p>0.05$, or highly significant ${ }^{* *}$ ) if $p<0.01$.

\section{Results}

A C-terminal peptide from the amyloid precursor protein can target NMNAT1 to axons in vitro

We hypothesized that N70 delivers NMNAT1, which is normally a nuclear protein (Schweiger et al., 2001; Berger et al., 2005), to 
axons and synapses in $\mathrm{Wld}^{\mathrm{S}}$ mice, where it prolongs their survival after injury. In transfected hippocampal cultures, we detected N70 exclusively outside the nucleus, and it was abundant in neurites. In contrast, we found overexpressed NMNAT1 only in the nucleus (supplemental Fig. 1, available at www.jneurosci.org as supplemental material). This is in line with previous reports showing presence of full-length Ube $4 \mathrm{~b}$ in the cytoplasm and axons in vivo (Mack et al., 2001; Fang et al., 2005). The unique 18 aa sequence of Wld ${ }^{\mathrm{S}}$ (Wld18) did not affect distribution (supplemental Fig. 1, available at www.jneurosci.org as supplemental material). Next, we fused several reported axonal targeting peptides $\mathrm{N}$-terminally to NMNAT1 that had been mutated in its nuclear localization sequence ( $\triangle$ NLS NMNAT1). The aim was to identify an axonal targeting tag that would mimic the N70-mediated targeting of NMNAT1. We tested the peptides GFPQNQKEGRCS from exon 7 of the survival motor protein (SMN) (Zhang et al., 2003), the cytoplasmic targeting sequence (MEM) MLCCMRRTKQVEKNDEDQKI from growth cone-associated protein (GAP-43) (Zuber et al., 1989), and GYENPTYKFFEQMQN from amyloid precursor protein intracellular domain (AICD) (Satpute-Krishnan et al., 2006). For comparative immunofluorescence all constructs were also FLAG tagged at their $\mathrm{C}$ terminus.

The efficiency of these peptides in targeting $\triangle$ NLS NMNAT1 to axons was compared in transfected hippocampal cultures. Axons were identified by morphological criteria and by immunostaining with the proximal axonal marker anti-ankyrin G (Kordeli et al., 1995). Only neurons with low-to-medium level of immunosignal were analyzed to avoid mislocalization due to overexpression. The 15-aa-long AICD sequence of APP (AICD$\triangle$ NLS NMNAT1-FLAG) was the most effective in redistributing $\triangle$ NLS NMNAT1 to the axon, especially to distal regions (Fig. $1 A)$. Although a little AICD- $\triangle$ NLS NMNAT1-FLAG was also present in MAP-2-positive dendrites, significantly more diffuse or dendritic staining was visible without targeting ( $\triangle$ NLS NMNAT1-FLAG) or in presence of the targeting sequence from exon 7 of SMN protein (Exon7 SMN- $\Delta$ NLS NMNAT1-FLAG). The MEM sequence of GAP- 43 caused toxicity and was therefore not examined further. Thus, the AICD- $\triangle$ NLS NMNAT1-FLAG construct (Fig. $1 B$ ) was selected for microinjection to produce axonally targeted NMNAT1 (Ax-NMNAT1) mice.

\section{Expression of Ax-NMNAT1 transgene at low doses}

We established six Ax-NMNAT1 hemizygous transgenic lines from seven founders (lines 1-4, 6-7) by breeding to YFP-H mice (Feng et al., 2000) for convenient assessment of Wallerian degeneration (Beirowski et al., 2004). Western blotting of brain homogenates revealed low levels of axonally targeted NMNAT1 protein in Ax-NMNAT1 mice using anti-FLAG antibody, that increased approximately twofold in line 2 when bred to homozygosity (Fig. 2A). Anti-NMNAT1 antibody 183 (Conforti et al., 2000) demonstrated that levels of Ax-NMNAT1 were substantially lower than $\mathrm{Wld}^{\mathrm{S}}$ in Wld ${ }^{\mathrm{S}}$ heterozygotes and NMNAT1 in NMNAT1-overexpressing transgenic mice (Conforti et al., 2007), respectively (Fig. 2B). In hemizygous line 1 Ax-NMNAT1 mice protein expression was below the detection limit, and only faintly visible in concentrated DRG samples from homozygous mice (see Fig. 4C). Because enzymatic NMNAT activity is essential for Wld ${ }^{\text {s }}$ neuroprotection (Araki et al., 2004; Jia et al., 2007; Conforti et al., 2009; Sasaki et al., 2009a) and measurements of NMNAT enzyme activity also allow quantitative assessment of transgenic protein levels (Conforti et al., 2007; Beirowski et al., 2009), we assayed total NMNAT activity in brains from AxNMNAT1 mice. Line 1 samples showed activity similar to wild-type
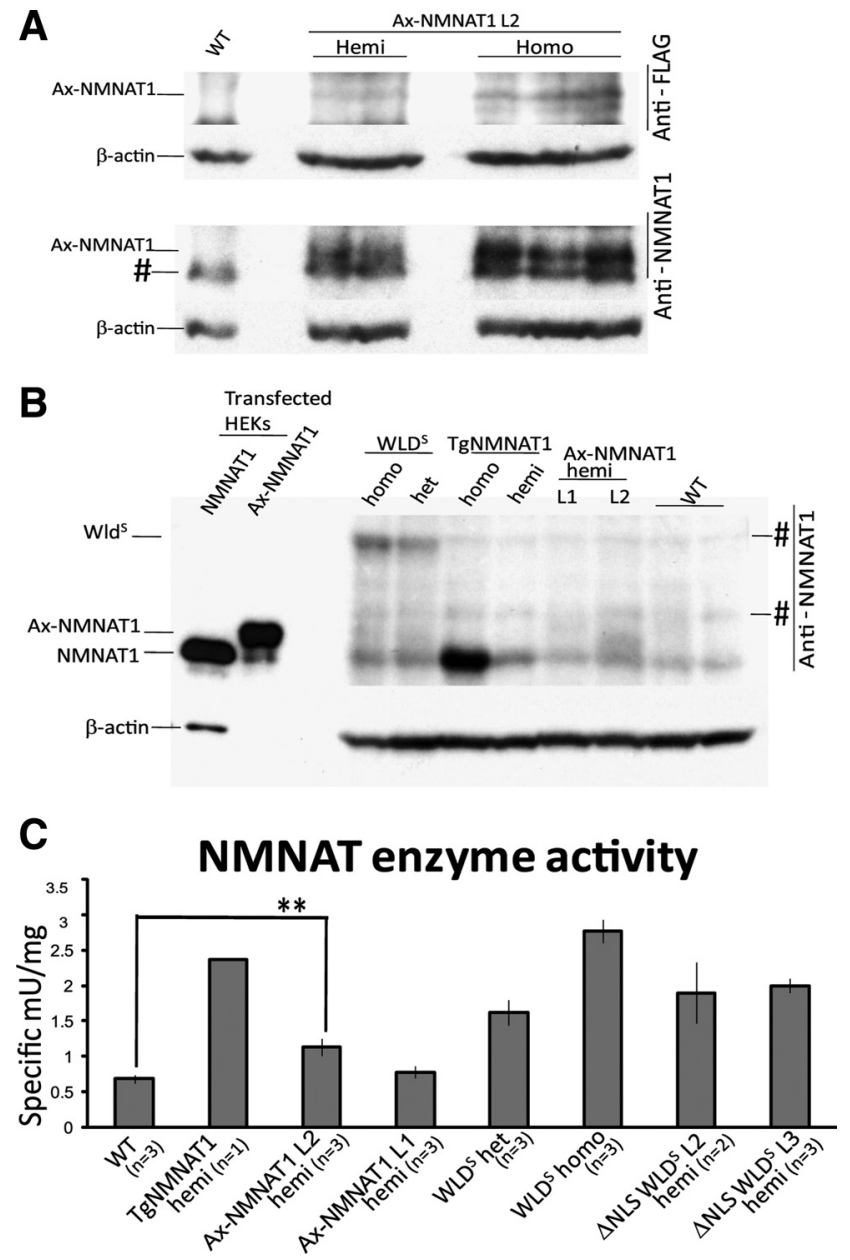

Figure 2. Axonally targeted NMNAT1 levels in brains of Ax-NMNAT1 mice from line 1 and 2 . $A$, Western blotting of Ax-NMNAT1 line 2 mouse brain homogenates showing approximately twofold higher expression level of Ax-NMNAT1 protein in homozygotes than in hemizygotes, by anti-FLAG antibody detection (top) and anti-NMNAT1 antibody detection (bottom). B, Representative anti-NMNAT1 (antibody 183) Western blot of total brain homogenates of AxNMNAT1 mice. Anti-NMNAT1 antibody 183 detects both NMNAT1 and WId ${ }^{\mathrm{S}}$. Axonally targeted NMNAT1 is 23 aa longer than murine native NMNAT1 and therefore migrates more slowly on SDS-polyacrylamide gel. Transfected HEK lysates indicate the molecular size of NMNAT1 and Ax-NMNAT1. Ax-NMNAT1-transfected HEK lysate is 10-fold diluted; thus, its loading control band ( $\beta$-actin) is not visible at this exposure time. In $\boldsymbol{A}$ and $\boldsymbol{B}$, \# indicates nonspecific band. $C$, Confirmation that axonally targeted NMNAT1 is enzymatically active in brain homogenates and that activity levels correlate with protein levels. Levels of NMNAT specific enzyme activity are higher in Ax-NMNAT1 mice from line 2 than in negative control littermates (WT). NMNAT enzyme activity of Ax-NMNAT1 mice from line 1 is similar to the WT one. Both Ax-NMNAT1 lines show levels lower than the ones from all the other strains. ${ }^{* *} p=0.0037$.

(WT) littermates, further indicating that transgene expression in this line is very low. Activity in line 2 was only slightly increased and remained significantly lower than that in $\mathrm{Wld}^{\mathrm{S}}$ heterozygotes (Fig. $2 C$ ). This confirmed that the fusion protein was enzymatically active and the specific values of NMNAT enzyme activity correlate with protein expression levels as detected by Western blotting. The absence of specific immunofluorescence on brain cryosections (supplemental Fig. 2, available at www.jneurosci.org as supplemental material) further confirms the lack of high transgene expression. The efficacy of the FLAG antibody was validated using controls from FLAG-tagged wild-type (WF) and frame-shifted (DF) superoxide dismutase transgenic mice (Watanabe et al., 2005) (supplemental Fig. 2, available at www.jneurosci.org as supplemental material). 


\section{Robust axon protection in vivo and in vitro}

An amount of $\mathrm{Wld}^{\mathrm{S}}$ protein comparable to this level of axonally targeted NMNAT1 would be unlikely to grant axonal protection in $\mathrm{Wld}^{\mathrm{S}}$ transgenics or at best have only a weak effect (Mack et al., 2001). Strikingly however, both Ax-NMNAT1 lines showed robust axonal protection, as did all four other Ax-NMNAT1 lines, which expressed the fusion protein at levels similar to or lower than line 2 (data not shown). Seven and fourteen days after transection, most axons were still intact in the distal stump of the sciatic nerve as assessed by YFP longitudinal imaging (Fig. $3)$. In clear contrast, all axons from WT and NMNAT1-overexpressing mice were completely fragmented as early as $3 \mathrm{~d}$ after nerve lesion as previously reported (Beirowski et al., 2004; Conforti et al., 2007), despite the higher transgene expression level in the latter.

Next, we examined axonal preservation $35 \mathrm{~d}$ after axotomy, a time point at which native $\mathrm{Wld}^{\mathrm{S}}$ no longer preserves axons. Continuous axons were consistently present in distal stumps of sciatic nerve from Ax-NMNAT1 L2 mice and in tibial nerves of both Ax-NMNAT1 lines, similar to the preservation by extranuclear $\mathrm{Wld}^{\mathrm{S}}\left(\Delta\right.$ NLS Wld $\left.^{\mathrm{S}}\right)$ (Fig. 3 and supplemental Fig. 3, available at www.jneurosci.org as supplemental material). Regeneration was ruled out in the distal stump by imaging the cut site, where all the intact axons originated from end bulbs (likely resulting from continued retrograde axonal transport), which mark the lesion site (supplemental Fig. 3, available at www. jneurosci.org as supplemental material). Moreover, degeneration in Ax-NMNAT1 nerves was clearly dose-dependent. Accordingly, in Ax-NMNAT1 line 3, which showed transgene instability, the degree of axonal protection correlated to protein expression level in each mouse of the same progeny (supplemental Fig. 4, available at www.jneurosci.org as supplemental material).

The comparison of Ax-NMNAT1 and $\Delta$ NLS Wld ${ }^{\mathrm{S}}$ lines with similar transgene expression levels indicated a stronger axon sparing activity of Ax-NMNAT1. Mice from line 1 of the $\Delta$ NLS Wld $^{\mathrm{S}}$ strain express undetectable level of transgenic protein (Beirowski et al., 2009), analogous to Ax-NMNAT1 line 1, but their tibial nerve axons show clearly more extensive fragmentation $14 \mathrm{~d}$ after lesion (supplemental Fig. 5, available at www.jneurosci.org as supplemental material).

Thus, Ax-NMNAT1 protects axons more robustly than $\mathrm{Wld}^{\mathrm{S}}$, even when expressed at substantially lower levels. Moreover, these data indicate that Ax-NMNAT1 confers higher axoprotective potency than extranuclear Wld ${ }^{\mathrm{S}}$ in vivo.
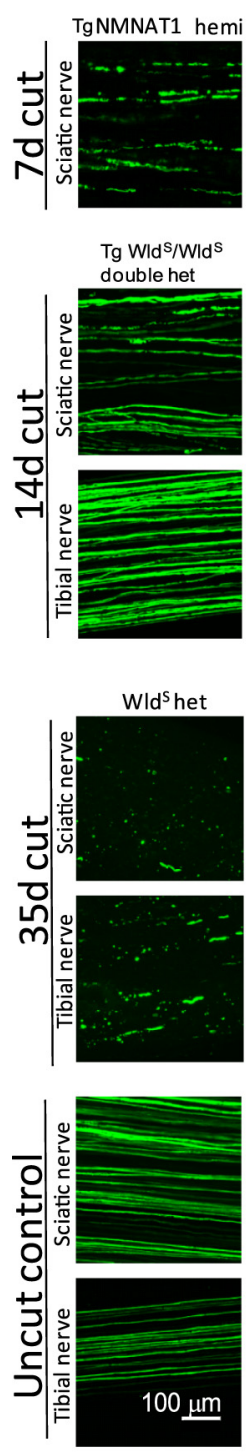
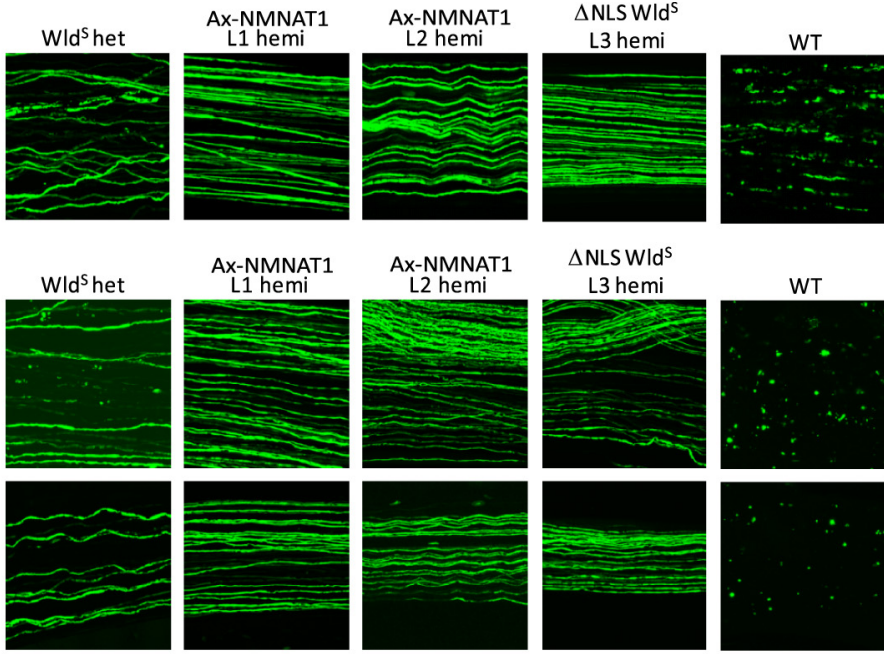

$\triangle \mathrm{NLSWId}^{\mathrm{S}}$
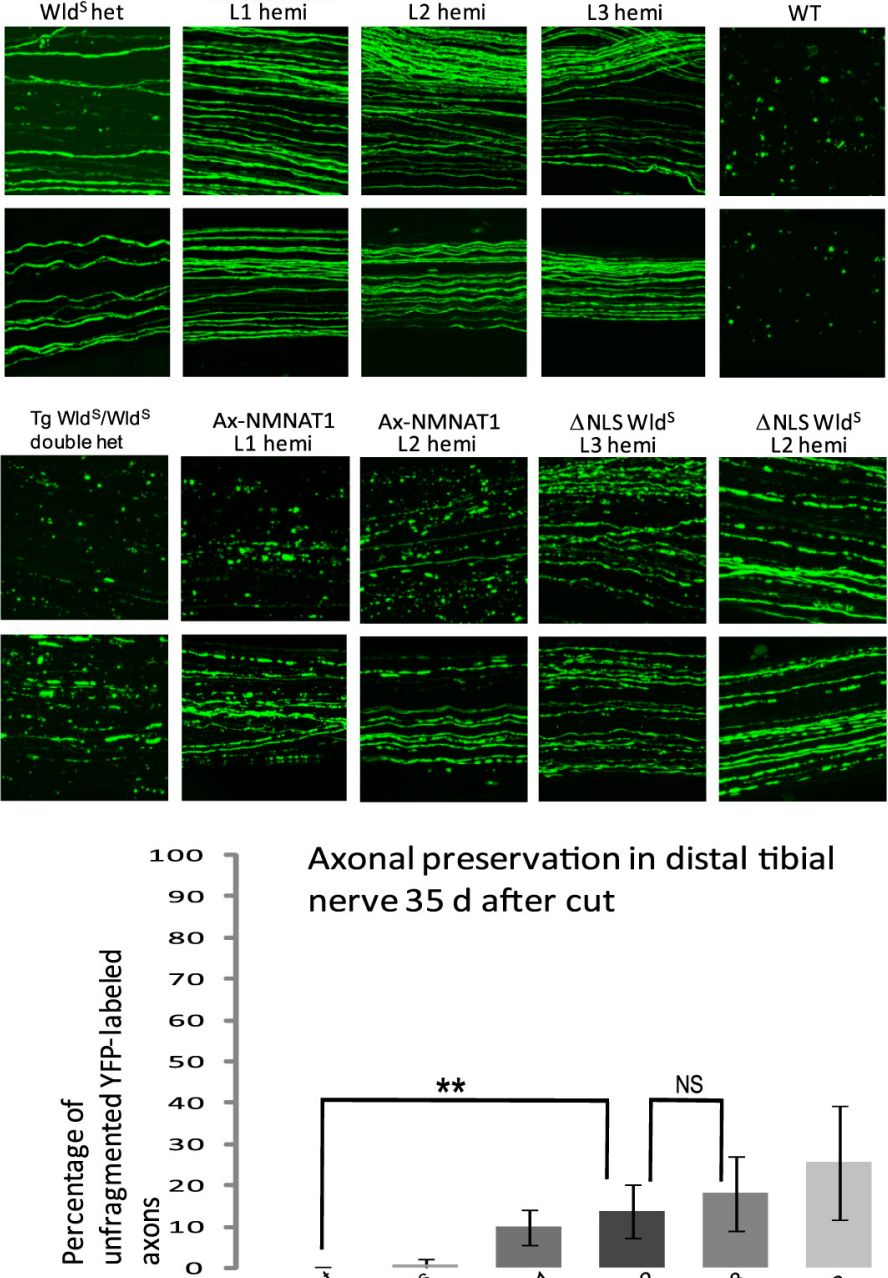

Axonal preservation in distal tibial nerve $35 \mathrm{~d}$ after cut

Figure 3. Comparison of delay of Wallerian degeneration in Ax-NMNAT1 mice and in mice with the indicated genotypes expressing YFP in a representative subset of neurons. Longitudinal imaging (confocal z-projections) of sciatic and tibial nerves 7 , 14 , and $35 \mathrm{~d}$ after transection, and quantification of percentages of intact axons in distal tibial nerves $35 \mathrm{~d}$ after lesion. Nerves from NMNAT1-overexpressing mice (TgNMNAT1) fragment with a time course similar to WT nerves, whereas $35 \mathrm{~d}$ lesioned nerves from hemizygous Ax-NMNAT1 mice still show intact axons. Thirty-five days after axotomy, the number of unfragmented axons in Ax-NMNAT1 samples is significantly higher than the one in WId ${ }^{5}$ samples and similar to the one in $\Delta \mathrm{NLS}$ WId ${ }^{S}$ samples. ( ${ }^{* *} p=0.003$, one-sample $t$ test; NS: $\left.p=0.399\right)$.

The efficacy was also evident in vitro using neurons from AxNMNAT1 mice (Fig. 4). We evaluated neurite survival up to $6 \mathrm{~d}$ after cutting in cultured DRG explants from hemizygous embryos of Ax-NMNAT1 line 1 and 2 both by identification of beading and fragmentation (Fig. 4A) and by quantitative software-based analysis of axonal continuity (Fig. $4 B$ ). For this purpose, we developed a formula that quantifies the degree of axonal protection, which we termed PI. PI calculates the area occupied by continuous axons versus the total axonal area in each imaged field and is near to 1 when all axons are intact. As fragmentation progresses after axotomy PI decreases, dropping to 


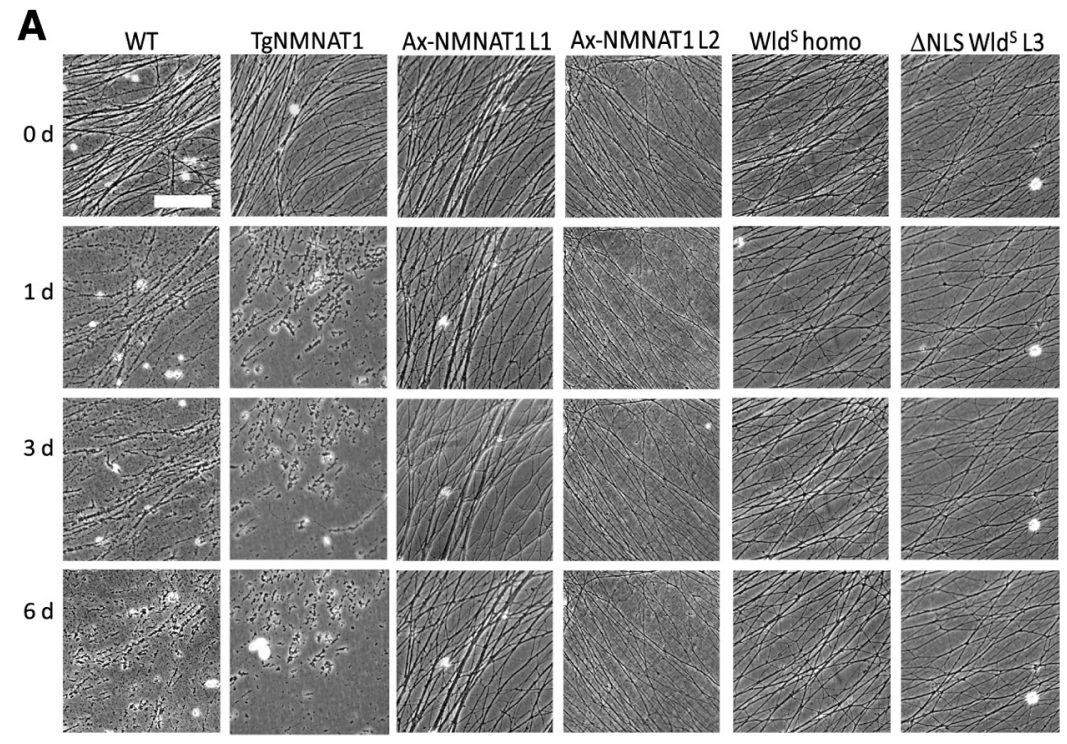

B In vitro neurite survival
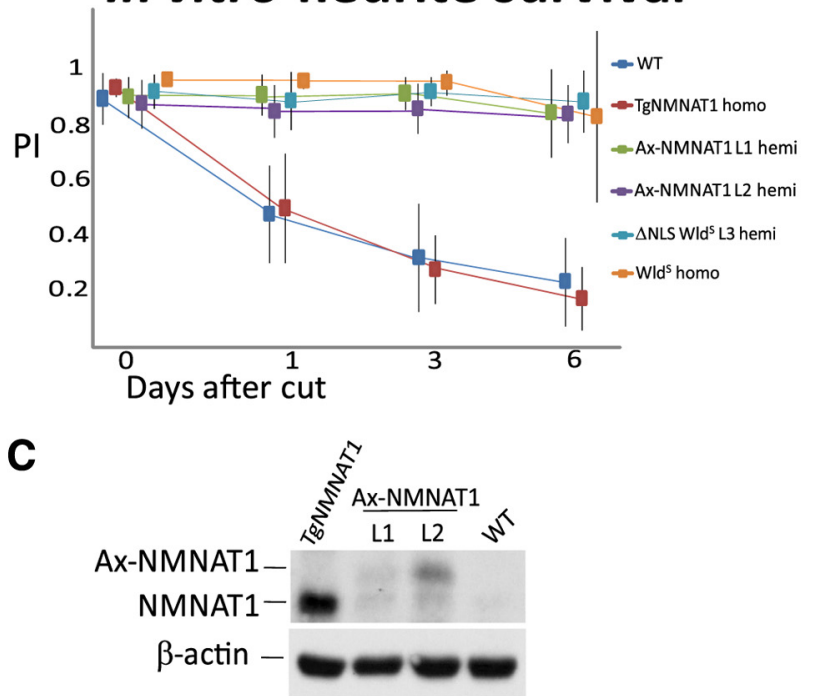

Figure 4. Neurite preservation after axotomy in DRG explant cultures from hemizygous Ax-NMNAT1 embryos. $\boldsymbol{A}$, Phasecontrast $0.3 \mathrm{~mm} \times 0.3 \mathrm{~mm}$ images of the same field at the time of transection, and 1,3, and $6 \mathrm{~d}$ after. Neurites from Ax-NMNAT1 explant cultures remain unfragmented for at least $6 \mathrm{~d}$ similar to neurites from spontaneous mutant WId ${ }^{5}$ and transgenic $\Delta$ NLS WId ${ }^{5}$ explant cultures. Neurites from homozygous NMNAT1-overexpressing (TgNMNAT1) embryos fragment within the first $24 \mathrm{~h}$. Scale bar, $0.1 \mathrm{~mm}$. B, Quantification of neurite continuity by assessment of the PI plotted against time after cutting. $\boldsymbol{C}$, Western blot probed with anti-NMNAT1 antibody 183, showing the respective transgenic protein expression in homozygous DRGs explant cultures. $\beta$-Actin is the loading control.

levels around 0.5 within the first $24 \mathrm{~h}$ for WT or DRGs from homozygous NMNAT1-overexpressing transgenic mice. By contrast, Ax-NMNAT1 neurites from both lines remained unfragmented for at least $6 \mathrm{~d}$ after cutting, similar to $\mathrm{Wld}^{\mathrm{S}}$ and $\Delta$ NLS Wld ${ }^{\mathrm{S}}$ neurites, with a PI constantly close to 1 (Fig. $4 B$ ). We confirmed high NMNAT1 expression in DRGs from NMNAT1 homozygotes, whereas Ax-NMNAT1 expression was low in homozygous cultures from line 2 (Fig. 4C). Remarkably, similar to the in vivo findings, Ax-NMNAT1 protein was detectable in Ax-NMNAT1 line 1 DRGs only if cultured from homozygotes (Fig. 4C), but remained below detection limit in hemizygous cultures (data not shown). Thus, whereas overexpressed nuclear NMNAT1 does not protect axons, axonally targeted NMNAT1 delays Wallerian degeneration similar to extranuclear $\mathrm{Wld}^{\mathrm{S}}$ in vivo and in vitro, despite the greatly reduced expression level.
Axonally targeted NMNAT1 localizes outside the nucleus in vivo at low levels Because the protective action is determined by extranuclear Wld $^{\mathrm{S}}$ (Beirowski et al., 2009) and is dose dependent (Mack et al., 2001), we compared extranuclear expression levels between Ax-NMNAT1 and other strains. Commercially available anti-NMNAT1 antibodies could barely detect native NMNAT1 in mouse lumbar spinal cord cryosections (Conforti et al., 2007). Thus, we based our comparison on Western blots of fractionated brain homogenates immunoblotted with antibody 183 , which we previously used for successful detection of NMNAT1 and Wld ${ }^{S}$ (Conforti et al., 2007). We confirmed that Ax-NMNAT1 protein is redistributed outside the nucleus in line 2 samples (Fig. 5 ), and found levels similar to the ones from the variant $\Delta \mathrm{N} 16 \mathrm{Wld}^{\mathrm{S}}$, which does not confer axon protection (Conforti et al., 2009). Densitometric quantification of cytoplasmic levels revealed that axonally targeted NMNAT1 is expressed $\sim 24.4 \%$ lower than $\mathrm{Wld}^{\mathrm{S}}$, and $\sim 96.5 \%$ lower than $\Delta \mathrm{NLS} \mathrm{Wld}^{\mathrm{S}}$ in the respective strains. Nevertheless, axonal preservation in AxNMNAT1 line 2 mice is greater than in $\mathrm{Wld}^{\mathrm{S}}$ and similar to $\Delta \mathrm{NLS} \mathrm{Wld}^{\mathrm{S}}$ mice from line 3 (Fig. 3), suggesting that axonal delivery of NMNAT1 markedly increases its efficacy.

\section{Axonally oriented NMNAT1 preserves motor nerve terminals robustly in young and adult mice}

Motor nerve terminal preservation decreases with age in homozygous spontaneous mutant and transgenic Wld ${ }^{\mathrm{S}}$ mice, and is absent in Wld ${ }^{\mathrm{S}}$ mice older than 3 months (Gillingwater et al., 2002). However, extranuclear $\mathrm{Wld}^{\mathrm{s}}$ can protect NMJs efficiently in aged mice (Beirowski et al., 2009). Thus, as a stringent test, we measured the efficacy of axonally targeted NMNAT1 at motor nerve terminals. Wld ${ }^{\mathrm{S}}$ would not be expected to delay denervation of NMJs at these expression levels, as motor nerve terminals in $\mathrm{Wld}^{\mathrm{S}}$ heterozygotes are not preserved following axotomy even at 1-2 months of age (Wong et al., 2009). First we imaged synaptic vesicle recycling (Fig. $6 \mathrm{~A}$ ) and recorded evoked action potentials by intracellular recordings in deep lumbrical and FDB muscles of 2-month-old hemizygous Ax-NMNAT1 mice from line 2 (Fig. $6 B)$. Both the morphological and the functional evaluation revealed a robust degree of NMJ preservation $6 \mathrm{~d}$ after axotomy. In Ax-NMNAT1 FDB and lumbrical muscles respectively, $69 \%$ and $67 \%$ of motor endplates were fully labeled by AM1-44 vital staining, showing complete innervation with synaptic vesicles recycling activity in $100 \%$ of their area $6 \mathrm{~d}$ after axotomy. In contrast, in Wld ${ }^{\mathrm{S}} \mathrm{FDB}$ and lumbrical muscles, only $38 \%$ and $42 \%$ of motor endplates retained full innervation $6 \mathrm{~d}$ after axotomy, in line with previous data (Gillingwater et al., 2002). In physiological record- 

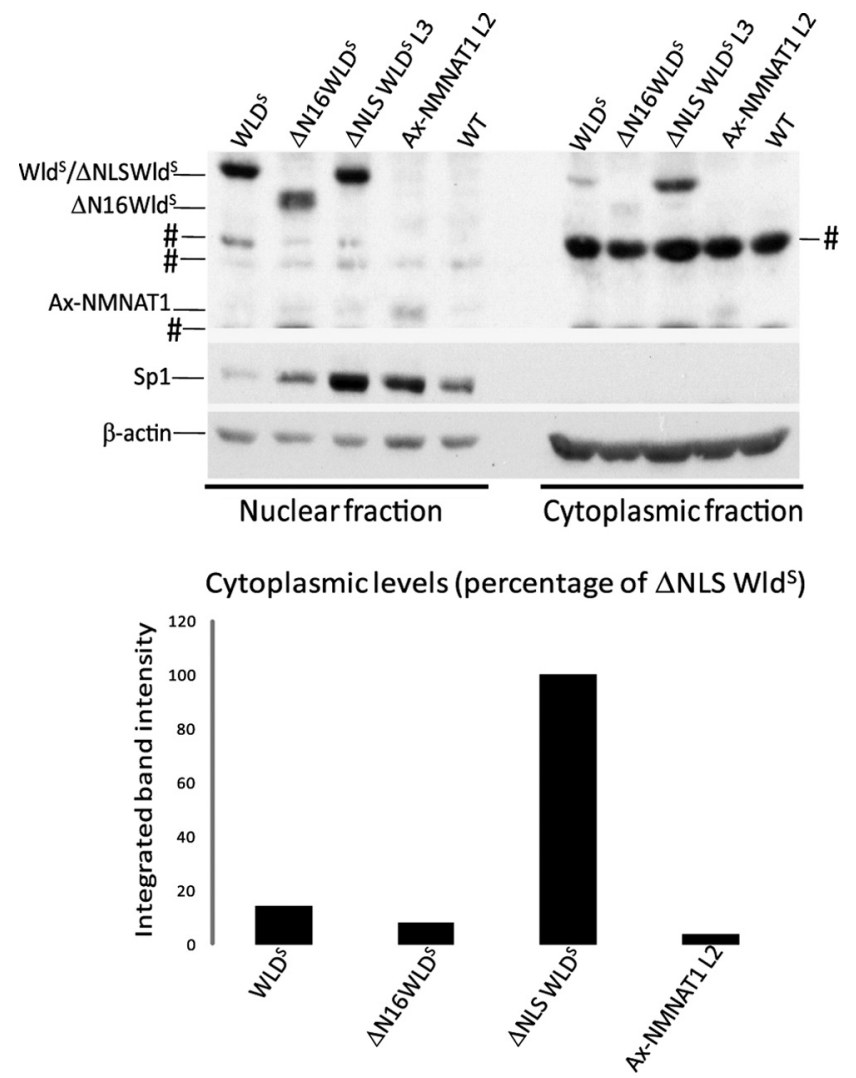

Figure 5. Cytoplasmic redistribution of axonally targeted NMNAT1. Representative Western blot of nuclear and postnuclear (cytoplasmic) fractions from brains of AxNMNAT1 mice in comparison to native WId ${ }^{5}$ mice, mice expressing the nonprotective variant of WId ${ }^{\mathrm{S}}$ lacking the first $16 \mathrm{~N}$-terminal amino acids $\left(\Delta \mathrm{N} 16 \mathrm{WId}{ }^{\mathrm{S}}\right.$ hemi), and mice expressing the enhanced protective extranuclear variant $\left(\Delta \mathrm{NLS}\right.$ WId ${ }^{S} \mathrm{~L} 3$ hemi) $(n=4)$. Nuclear and cytoplasmic factions, blotted with anti-NMNAT1 antibody 183 (top left and right), are shown at different exposure times to optimize the visualization of the faint bands (Ax-NMNAT1, WId ${ }^{S}$, and $\Delta$ N16WId ${ }^{S}$ ). Sp1 is the loading control for the nuclear fraction. The densitometry (bottom) shows the intensity of the cytoplasmic bands, normalized to $\beta$-actin, and is expressed as percentage of $\Delta$ NLS WId ${ }^{S}$ levels for comparative analysis. The axonally targeted NMNAT1 protein shows the lowest levels if compared to WId ${ }^{S}$ and variants in the other strains. "Nonspecific band.

ings, $62.2 \%$ of fibers showed nerve evoked endplate potentials (EPPs). The extent of the NMJ preservation measured physiologically in this way was at least as strong as that of age-matched Wld ${ }^{\mathrm{S}}$ homozygotes (Fig. $6 \mathrm{~B}$ and supplemental Fig. 5, available at www.jneurosci.org as supplemental material). Next, we made similar measurements in $6 \mathrm{~d}$ lesioned hemizygous Ax-NMNAT1 mice older than 6 months (Fig. $6 A, C$ ). As expected age-matched Wld ${ }^{S}$ homozygotes showed almost complete denervation and neither spontaneous nor evoked action potentials. Remarkably, muscles from these older Ax-NMNAT1 mice still recycled synaptic vesicles and responded to electrophysiological stimulation with evoked EPPs (average of $35.56 \%$ of fibers per muscle). An additional $18.87 \%$ of fibers per muscle did not respond to nerve stimulation but did show evidence of spontaneous miniature endplate potentials (MEPPs). Morphological preservation of nerve terminals was also evident in axotomized adult Ax-NMNAT1 mice from line 1 by imaging of YFP-labeled motor nerve terminals (supplemental Fig. 6, available at www.jneurosci.org as supplemental material). Thus, axonally targeted NMNAT1 confers enhanced efficacy for NMJ preservation. The level of synaptic protection appears similar to that reported in our previous study of transgenic mice in which full-length Wld ${ }^{\mathrm{S}}$ protein was targeted away from its normal nuclear localization (Beirowski et al., 2009).

\section{Delivery of NMNAT1 to axons is necessary for axon protection}

To test whether axonal delivery of NMNAT activity is necessary for axon protection as well as sufficient, we examined the effect of blocking axonal delivery of the Ax-NMNAT1 protein. In initial experiments, we added a dileucine (LL) dendrite targeting peptide from Shal $\mathrm{K}^{+}$channels-FETQHHHLLHCLEKTT (Rivera et al., 2003)—but found that this was not sufficient to achieve complete exclusion from the axonal compartment in hippocampal and DRG neurons (data not shown). Considering that only very low levels of Ax-NMNAT1 are needed to protect axons (e.g., in line 1 hemizygotes), it is important to block axonal delivery more completely to test this hypothesis.

Therefore we inhibited entry of Ax-NMNAT1 into axons pharmacologically immediately after it was expressed. DRG neurons were transfected with Ax-NMNAT1-mCherry and at the same time treated with high concentration of vincristine $(0.04$ $\mu \mathrm{M})$ or nocodazole $(20 \mu \mathrm{g} / \mathrm{ml})$, to achieve fast and complete disruption of axonal transport. Ax-NMNAT1-mCherry protein was expressed in presence of drugs, but restricted to the soma and proximal neurites (supplemental Fig. 8, available at www. jneurosci.org as supplemental material). DRGs were axotomized $24 \mathrm{~h}$ later (Fig. 7Aii,Aiv,Bii,Biv). When axonal transport was blocked before Ax-NMNAT1-mCherry protein was expressed, axonal preservation after axotomy was greatly reduced. In contrast, axonal sparing was robust if drugs were applied $24 \mathrm{~h}$ after transfection, at the time of cut, allowing time for prior synthesis and axonal targeting of some Ax-NMNAT1 protein (Fig. 7A-C). Only $5 \%$ and $19 \%$ of axons remained free of extensive varicosities or did not fragment $48 \mathrm{~h}$ after cut when microtubules were destabilized early by nocodazole and vincristine, respectively (Fig. 7 Cii,Civ), compared to $69 \%$ of axons preserved in absence of drugs. If microtubules were disrupted at the time of axotomy, $24 \mathrm{~h}$ after Ax-NMNAT1 expression and axonal delivery, axotomized neurites were preserved as strongly as in absence of drugs (Fig. 7Ci,Ciii). Thus, preventing axonal NMNAT1 entry abolishes the protective capacity.

Although the drug treatment induces some axonal varicosities (supplemental Fig. 8, available at www.jneurosci.org as supplemental material), a general neuronal intoxication is not responsible for the neurite degeneration above because Ax-NMNAT1 can protect in presence of vincristine and nocodazole, if drugs are applied the time of axotomy. As a further control for this, we applied nocodazole at a lower concentration $(5 \mu \mathrm{g} / \mathrm{ml})$, obtaining similar results, with a reduction of axonal survival to $29 \%$ when nocodazole was applied at the time of transfection (Fig. 7C). The slightly higher survival compared to the result obtained with 4 times more concentrated nocodazole $(20 \mu \mathrm{g} / \mathrm{ml})$ may reflect the lower effectiveness of microtubule destabilization, and thus the lower efficacy of preventing AxNMNAT1 from entering axons.

Wld ${ }^{\mathrm{S}}$ explant cultures are known to be resistant to vincristine toxicity (Conforti et al., 2009), and explants from Ax-NMNAT1 transgenic embryos can be cultured for several days before axotomy, allowing longer time for expression and axonal delivery of axonally targeted NMNAT1 stably. Thus, we axotomized DRG explants from Ax-NMNAT1 line 1 homozygotes $6 \mathrm{~d}$ after plating (Fig. 7D). To mimic the conditions of our previous transfected DRGs, we pretreated the explants with high concentrations of vincristine or nocodazole for $24 \mathrm{~h}$ before neurite transection. Six days after cut, neurites of Ax-NMNAT1 cultures were still intact 


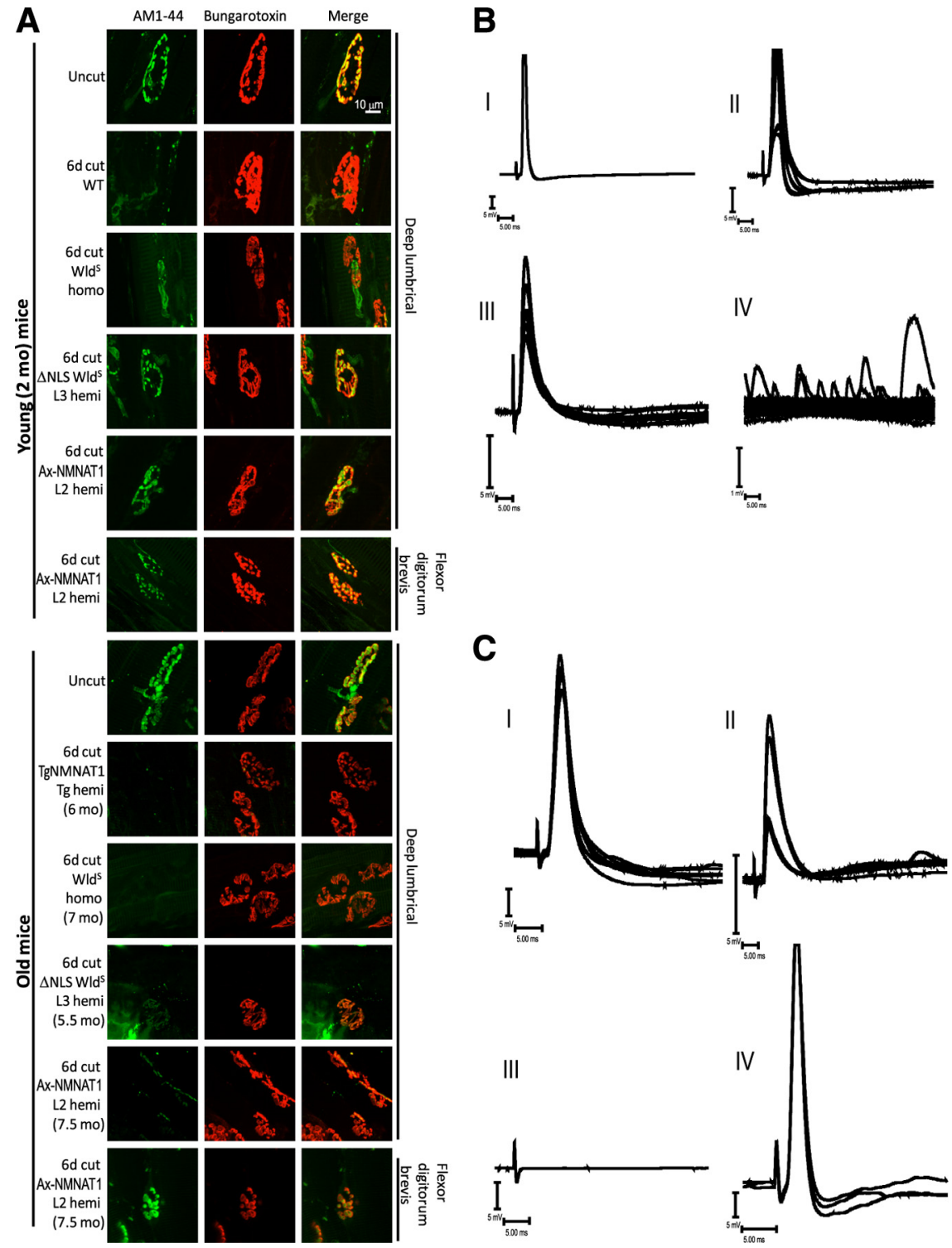

Figure 6. Neuromuscular junctions in Ax-NMNAT1 mice remain functional for at least $6 \mathrm{~d}$ after axotomy in young ( 2 months old ) and adult ( $>6$ months old) mice. $A$, Confocal projections showing alignment of vital staining of presynaptic motor nerve terminals (AM1-44, green) with postsynaptic acetylcholine receptors (TRITC-BTX, red) in lumbrical and FDB muscles of mice of the indicated genotype and age. Protection was weak at this time point in young Wld ${ }^{S}$ homozygotes and absent in older (6 months) WId homozygotes but appeared equally strong at both ages in Ax-NMNAT1 mice. $\boldsymbol{B}$, Intracellular recordings showing evoked (I-III) and spontaneous (IV) responses in 4 different FDB muscle fibers from 2-month-old Ax-NMNAT1 hemizygotes (line 2), $6 \mathrm{~d}$ after axotomy. The peaks of evoked action potential are clipped in $\boldsymbol{B I}$ and $\boldsymbol{B I I}$. $\boldsymbol{B I}$, Response to single tibial nerve stimulus; $\boldsymbol{B} \boldsymbol{I I}$, superimposed traces at $1 \mathrm{~Hz}$ stimulation showing EPPs with reduced quantal content near the firing threshold; $B$ III, subthreshold EPPs; $B I V$, spontaneous MEPPs recorded in several superimposed sweeps on a free-running time base. $C$, Intracellular recordings of synaptic potentials recorded from FDB muscle fibers of 6-month-old Ax-NMNAT1 mice $(I, I I)$ and of 5.5-month-old WII ${ }^{5}$ homozygotes (III) $6 \mathrm{~d}$ after axotomy, and from unlesioned contralateral controls (IV). CI, Superimposed subthreshold EPPs in axotomized Ax-NMNAT1 FDB muscle. CII, Subthreshold EPPs and a MEPP in axotomized Ax-NMNAT1 FDB muscle. CIII, No evoked action potential visible in WId ${ }^{S}$ muscle. $C I V$, Expected evoked action potentials in an unlesioned fiber.

maintaining a PI around 0.8 , similarly to Ax-NMNAT1 neurites axotomized in absence of drugs (Fig. $4 B$ ). Cultures from C57BL/6 mice started to fragment $24 \mathrm{~h}$ after treatment and were completely degenerated $6 \mathrm{~d}$ after axotomy, with a PI around 0.3 (Fig. $7 E, F$ ). This further shows that the longer drug treatment is also not itself responsible for the neurite degeneration.

Thus, if Ax-NMNAT1-mCherry is allowed to enter axons freely, it protects them after mechanical injury, and from microtubule destabilization, including nocodazole toxicity. However, this protection depends on axonal transport.
Axonally targeted NMNAT1 localizes to vesicular fractions and it is cotransported with mitochondria

The potency of Ax-NMNAT1 in protecting axons and synapses suggests that axonally targeted NMNAT1 is delivered with high efficiency to the location where Wld ${ }^{\mathrm{S}}$ functions. To investigate the specific subcellular localization of Ax-NMNAT1 protein, we fractionated brains of Ax-NMNAT1 mice and (variant) $\mathrm{Wld}^{\mathrm{S}}$ mice by sequential centrifugation at increasing speeds. We obtained fractions differently enriched in organelles as validated by nuclear, mitochondrial, endoplasmic reticulum (ER), Golgi, and synaptic vesicle markers (Fig. 8 A). The distribution of Ax-NMNAT1 and (variant) Wld ${ }^{S}$ mostly resembled the one of synaptic vesicles, with particular abundance in vesicle fractions V0 and V1, where also ER and Golgi markers were present. These proteins, and particularly Ax-NMNAT1, were abundant also in the mitochondrial fraction (M) (Fig. 8 B). Thus, we find here that both Ax-NMNAT1 and Wld $^{S}$ are mostly concentrated in a small membranous compartment in vivo, extending our previous finding of high levels of (variant) $\mathrm{Wld}^{\mathrm{S}}$ in mitochondria and microsome fractions and fine granular staining of extranuclear Wld ${ }^{\mathrm{S}}$ in sciatic nerve axoplasm (Beirowski et al., 2009).

Next, we studied this site using an in vitro imaging approach. Because of the lack of commercially available, sensitive antibodies for detection of Ax-NMNAT1 protein, we fused Ax-NMNAT1 to mCherry to observe the fluorescence directly in transfected hippocampal (Fig. 9A-D) and dissociated DRG neurons (Fig. 9E-K). Ax-NMNAT1-mCherry was distributed in vitro in pleomorphic vesicle-tubular structures. Similar structures were also evident in transfected non-neuronal cells that are present at low numbers in our DRG cultures (supplemental Fig. 7, available at www.jneurosci.org as supplemental material). Vesicles entered the axons (Fig. 9B) and, particularly in DRG neurons, were concentrated at the growth cones (Fig. 9F), where the fluorescence appeared clearly punctate (Fig. 9G, arrowheads). Next, we assessed colocalization with extranuclear $\mathrm{Wld}^{\mathrm{S}}$ by cotransfection with $\Delta$ NLS Wld ${ }^{\mathrm{S}}$ EGFP (Beirowski et al., 2009). $\Delta$ NLS Wld ${ }^{\text {s}}$-EGFP and AxNMNAT1-mCherry gave a similar vesicle-tubular distribution, and we noticed partial colocalization in soma (Fig. $9 C, D, H$ ) and particularly in puncta along axons (Fig. 9C,D,I).

Finally, we assessed the identity of these structures by testing for colocalization (supplemental Fig. 8, available at www. jneurosci.org as supplemental material) with the same organelle markers used in the subcellular fractionation experiment (Fig. 8), along with additional markers of trans-Golgi-network/ER 
(calsyntenin-1) and microtubules ( $\beta$ tubulin). There was some heterogeneity, with Ax-NMNAT1-mCherry fluorescence occasionally overlapping with Golgi staining $(\gamma$-adaptin $)$ in the soma, and more frequent colocalization with MitoTracker within axons (Fig. 9J). Time-lapse imaging in both DRG (Fig. $9 K$ and supplemental Movie 1, available at www.jneurosci.org as supplemental material) and hippocampal neurons (supplemental Movie 2, available at www.jneurosci.org as supplemental material) revealed a number of Ax-NMNAT1mCherry particles undergoing bidirectional axonal transport coordinated with movements of mitochondria. This is important because it is highly unlikely to reflect coincidental or transient colocalization. Velocity of mitochondria movement was similar in transfected and untransfected neurons with pauses between continuous transport (supplemental Movie 2, available at www. jneurosci.org as supplemental material), as described previously (Takenaka et al., 1990; Kang et al., 2008). The colocalization was evident on both static and moving mitochondria (supplemental Movie 1, available at www.jneurosci.org as supplemental material).

Together, these in vivo and in vitro data indicate that the highly protective axonally targeted NMNAT1 concentrates to the same subcellular structures where extranuclear $\mathrm{Wld}^{\mathrm{S}}$ is also trafficked. Ax-NMNAT1 transport is regulated and at least partially coordinated with the axonal movement of mitochondria, pointing to a contribution by mitochondria to the delivery of Ax-NMNAT1 and Wld ${ }^{\mathrm{S}}$ into axons.

\section{Discussion}

These data show that local delivery of NMNAT1 is essential to delay axonal and synaptic degeneration, and that even a marginal increase in NMNAT activity in axons is robustly protective. We extend previous work showing that $\mathrm{Wld}^{\mathrm{S}}$ protects axons against drugs affecting microtubule stability, demonstrating Ax-NMNAT1 protection also against nocodazole toxicity for the first time. Ax-NMNAT1 transport to axons was necessary to prevent degeneration, and its presence within axons was sufficient to overcome toxicity from high doses of axonal transport blockers. This indicates an axonal mechanism of protection, consistent with the presence of $\mathrm{Wld}^{\mathrm{S}}$ in mouse distal stumps 1 week after lesion (Beirowski et al., 2009).

Our data also show that NMNAT1 can be transformed into a highly potent neuroprotective molecule by axonal targeting. We show here that when targeted to axons by a specific targeting motif NMNAT1 acquires an efficacy greater than Wld ${ }^{S}$. We resolve the question of whether 15 -fold overexpression of extranuclear NMNAT1 is necessary for protection in vivo (Sasaki et al.,

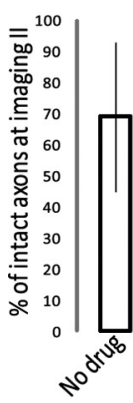
$B, E, F, 0.1 \mathrm{~mm}$.

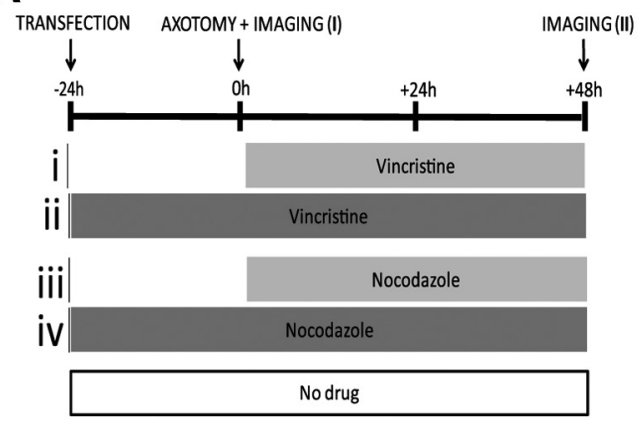

B

C Axonal preservation of transfected neurons
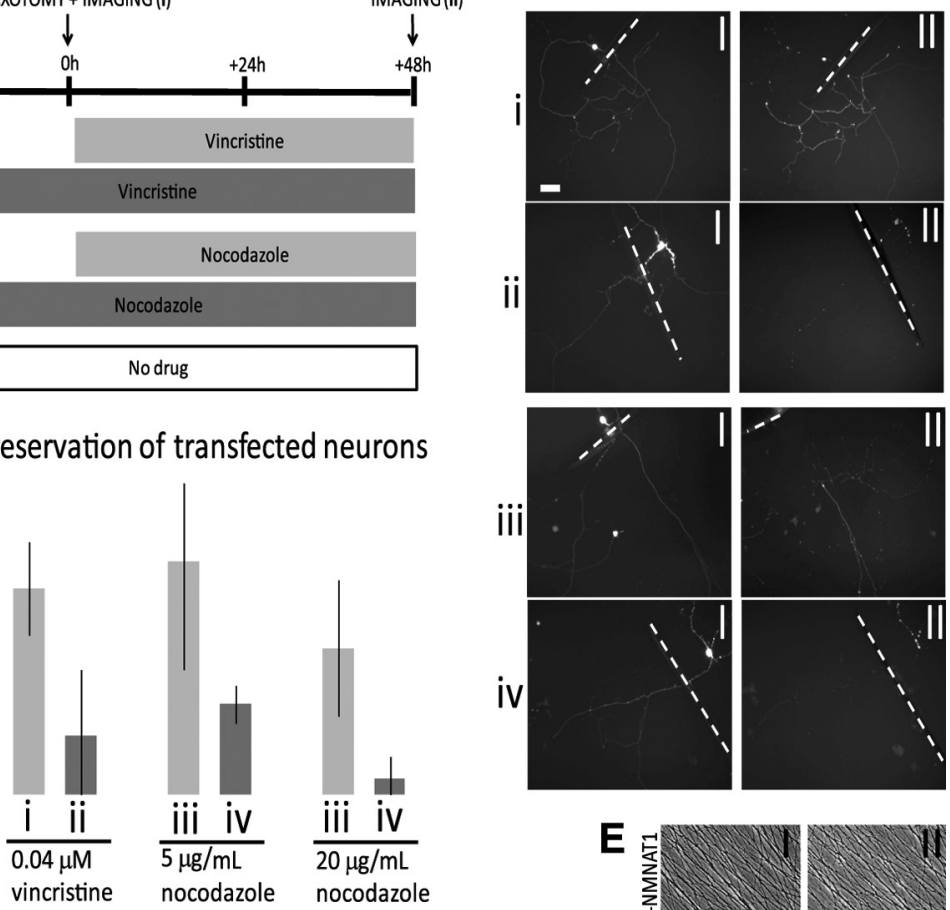

E
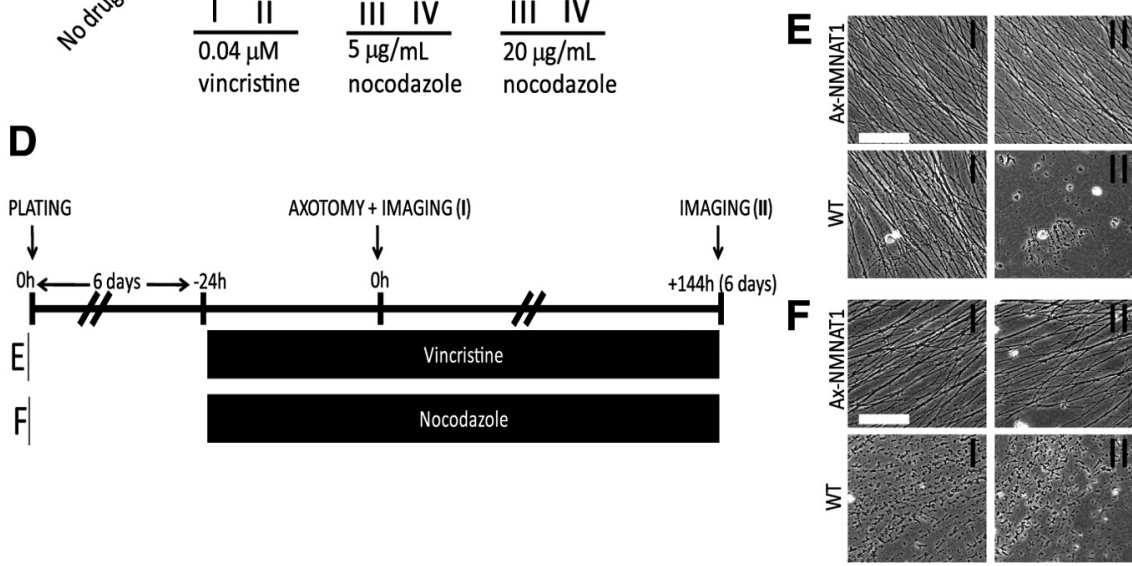

Figure 7. Blockage of axonal entry abolishes Ax-NMNAT1 protective capacity. $\boldsymbol{A}$, Diagram illustrating vincristine and nocodazole application (gray bars) at the indicated times to DRG neurons coexpressing EGFP and Ax-NMNAT1-mCherry. Vincristine was applied at $0.04 \mu \mathrm{m}$ (i and iii), and nocodazole at 5 or $20 \mu \mathrm{g} / \mathrm{ml}$ (iiii and $\mathbf{i v}$ ), at the time of transfection (ii and $\mathbf{i v}$ ), or $24 \mathrm{~h}$ later at the time of axotomy ( $i$ and iii). $B$, Representative EGFP epifluorescence images of DRGs expressing Ax-NMNAT1-mCherry, at the time of axotomy (I) and $48 \mathrm{~h}$ later (II), treated with $0.04 \mu \mathrm{m}$ vincristine (i and $\boldsymbol{i i}$ ), or with $20 \mu \mathrm{g} / \mathrm{ml}$ nocodazole (iii and $\boldsymbol{i v}$ ), at the times indicated in $A$. Dashed line marks the cut location. C, Quantification of axonal preservation $48 \mathrm{~h}$ after axotomy (imaging II) in DRGs cultured and treated as explained in $\boldsymbol{A}$. The diagram shows the percentage of axons ( \pm SD) that did not develop swelling or fragmentation between imaging I and imaging II. $\boldsymbol{D}$, Diagram illustrating $0.04 \mu \mathrm{m}$ vincristine, and $20 \mu \mathrm{g} / \mathrm{ml}$ nocodazole treatments on DRG explant cultures from wild-type mice and Ax-NMNAT1 homozygotes from line 1. Treatments started $6 \mathrm{~d}$ after plating, $24 \mathrm{~h}$ before axotomy. $\boldsymbol{E}$, Phase-contrast images $(0.3 \mathrm{~mm} \times 0.3 \mathrm{~mm})$ of Ax-NMNAT1 or wild-type explants, as indicated, at the time of cut $(\boldsymbol{I})$ and $6 \mathrm{~d}$ later $(\boldsymbol{I I})$, treated with vincristine as illustrated in $\boldsymbol{D}$. $\boldsymbol{F}$, Phase-contrast images $(0.3 \mathrm{~mm} \times 0.3 \mathrm{~mm})$ of Ax-NMNAT1 or wild-type, as indicated, at the time of cut $(\boldsymbol{I})$ and 6 d later $(\boldsymbol{I I})$, treated with nocodazole as illustrated in $\boldsymbol{D}$. Scale bars:

2009b), demonstrating that very low levels preserve axons and their synaptic endings if NMNAT1 is axonally targeted. Western blotting with two different primary antibodies, immunohistochemistry and NMNAT enzyme assays unanimously indicated low to undetectable levels of expression of Ax-NMNAT1 in transgenic mice. Because Wld ${ }^{\mathrm{S}}$ protective efficacy is dose dependent (Mack et al., 2001), axon protection would not be expected at such low levels, but low doses of axonally targeted NMNAT1 delay Wallerian degeneration for even 5 weeks. Moreover, neither a heterozygous dose of $\mathrm{Wld}^{\mathrm{S}}$ protein in young mice nor a homozygous dose in older mice is sufficient to delay NMJ dener- 


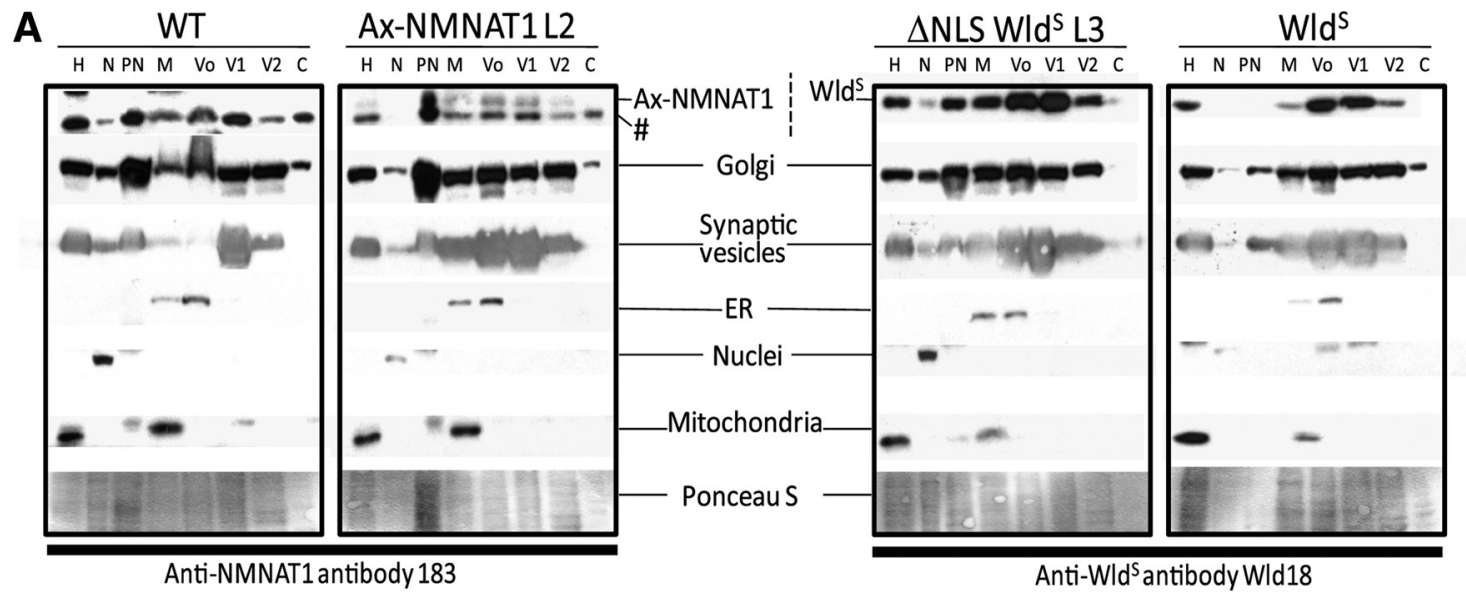

\section{B Densitometry of}

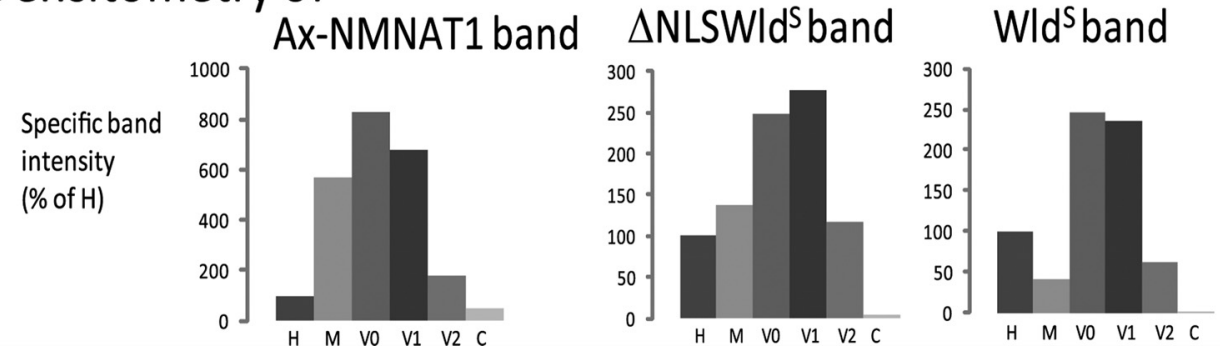

Figure 8. Localization of Ax-NMNAT1 protein in subcellular fractions. $A$, Brain subcellular fractions from hemizygous Ax-NMNAT1 mice, and variant and native WId ${ }^{S}$ mice (blots representative of 3 independent experiments). Membranes from negative littermate (WT) and Ax-NMNAT1 mice were probed with anti-NMNAT1 antibody 183 (left two panels) and membrane from $\Delta$ NLS WId ${ }^{S}$ and WId ${ }^{S}$ mice were probed with WId18 antibody (right two panels). Additional probing with the organelle markers validates fraction purity: anti-adaptin $\gamma$ for Golgi-enriched fractions, anti-p38 SNPH for synaptic vesicles-enriched fractions, anti-calnexin for ER-enriched fractions, anti-Sp1 for nuclear-enriched fractions, and anti-prohibitin for mitochondrial-enriched fractions. $\mathrm{H}$, Total homogenate; N, nuclear-enriched fraction; PN, postnuclear fraction; M, mitochondrial-enriched fraction; Vo, V1, V2, vesicle fractions; C, cytosol. Ponceau S indicates the amount of loaded protein. $\boldsymbol{B}$, Densitometry of Ax-NMNAT1, $\Delta$ NLS WId ${ }^{S}$, and WII ${ }^{S}$ band intensity in the respective organelle-enriched fractions. Because in each fraction the quantified protein is depleted or concentrated from the total homogenate, the intensities are expressed as percentage of the band intensity in the respective $\mathrm{H}$ fraction. Ax-NMNAT1 and (variant) WId ${ }^{5}$ protein appear concentrated in vesicle fractions with intensity correlating with the P38 SNPH intensity, and Ax-NMNAT1 is particularly concentrated also in the mitochondrial fraction.

vation (Gillingwater et al., 2002; Wong et al., 2009), whereas these very low doses of axonally targeted NMNAT1 preserve axotomized NMJs for $6 \mathrm{~d}$ and retain this ability even in older mice. Even though Ax-NMNAT1 has substantially higher potency than $\mathrm{Wld}^{\mathrm{S}}$, important similarities indicate that its mechanism of protection is the same as the Wld ${ }^{\mathrm{S}}$ mechanism. Ax-NMNAT1 protection efficacy was also dose dependent, and axonal atrophy and fragmentation in Ax-NMNAT1 mice followed a proximo-distal gradient (Beirowski et al., 2005).

These data strongly suggest that Wld ${ }^{\mathrm{S}}$ acts locally within axons. We cannot rule out the possibility that low somatic NMNAT1 activity increases the expression or transport of an axonal effector, but this seems unlikely in view of our previous data demonstrating that a truncated form of Wld ${ }^{\mathrm{S}}, \Delta \mathrm{N} 16 \mathrm{Wld}^{\mathrm{S}}$, is inefficient in protecting axons despite its extranuclear localization and enzymatic activity (Conforti et al., 2009).

An axonal role for Wld ${ }^{\mathrm{S}}$ and Ax-NMNAT1 has several interesting implications for the mechanism of Wallerian degeneration and synapse loss in disease. It has been postulated that depletion below a critical threshold of transported substances essential for axonal integrity triggers Wallerian degeneration (Lubińska, 1977). We recently identified NMNAT2 as a survival factor in wild-type axons (Gilley and Coleman, 2010). We proposed that in Wld ${ }^{S}$ nerves axonal delivery of this NMNAT1 fusion protein compensates for the postinjury depletion of NMNAT2. This study now confirms one key prediction of that proposal: that Wld ${ }^{\mathrm{S}}$ itself acts in axons.
Additionally as the peculiar degeneration of $\mathrm{Wld}^{\mathrm{S}}$ axons proceeds proximo-distally independently from the type of injury (Beirowski et al., 2005), this could reflect a spatial gradient of Wld ${ }^{\mathrm{S}}$ loss along the nerve. The weaker Wld ${ }^{\mathrm{S}}$ protection at NMJs, compared to the axonal trunk (Gillingwater et al., 2002), could be explained by the longer distance that $\mathrm{Wld}^{\mathrm{S}}$ needs to travel to reach the nerve endings and by dilution into the extensive terminal axonal branches. The age dependence of synapse withdrawal could be due to progressive decrement of axonal transport efficiency correlating with aging. At least in some cases, axonal transport decreases along the nerve with a proximo-distal gradient (Brunetti et al., 1987). Indeed NMNAT could have a local synaptic role since the single Drosophila NMNAT isoform is also localized at NMJs (Zhai et al., 2006).

The same model could explain why Wld $^{\mathrm{S}}$ retards anterograde degeneration more effectively than retrograde degeneration in some models of Parkinson's disease (Cheng and Burke, 2010). Consistent with this, optimizing the delivery of extranuclear NMNAT1 in this present report enhances NMJ protection in older mice. This is particularly important for pathologies in which synapses are affected at early stages, such as amyotrophic lateral sclerosis (ALS). Wld ${ }^{\mathrm{S}}$ has been proven protective for axons in many diseases but was relatively ineffective in SOD $1^{\mathrm{G} 93 \mathrm{~A}}$ transgenic mice, the most widely used model for familial ALS (Coleman, 2005; Fischer et al., 2005), and failed to reduce symptoms in others (Mi et al., 2005). Interestingly, although protection depends on transport of NMNAT1 to axons, degeneration caused by axonal trans- 

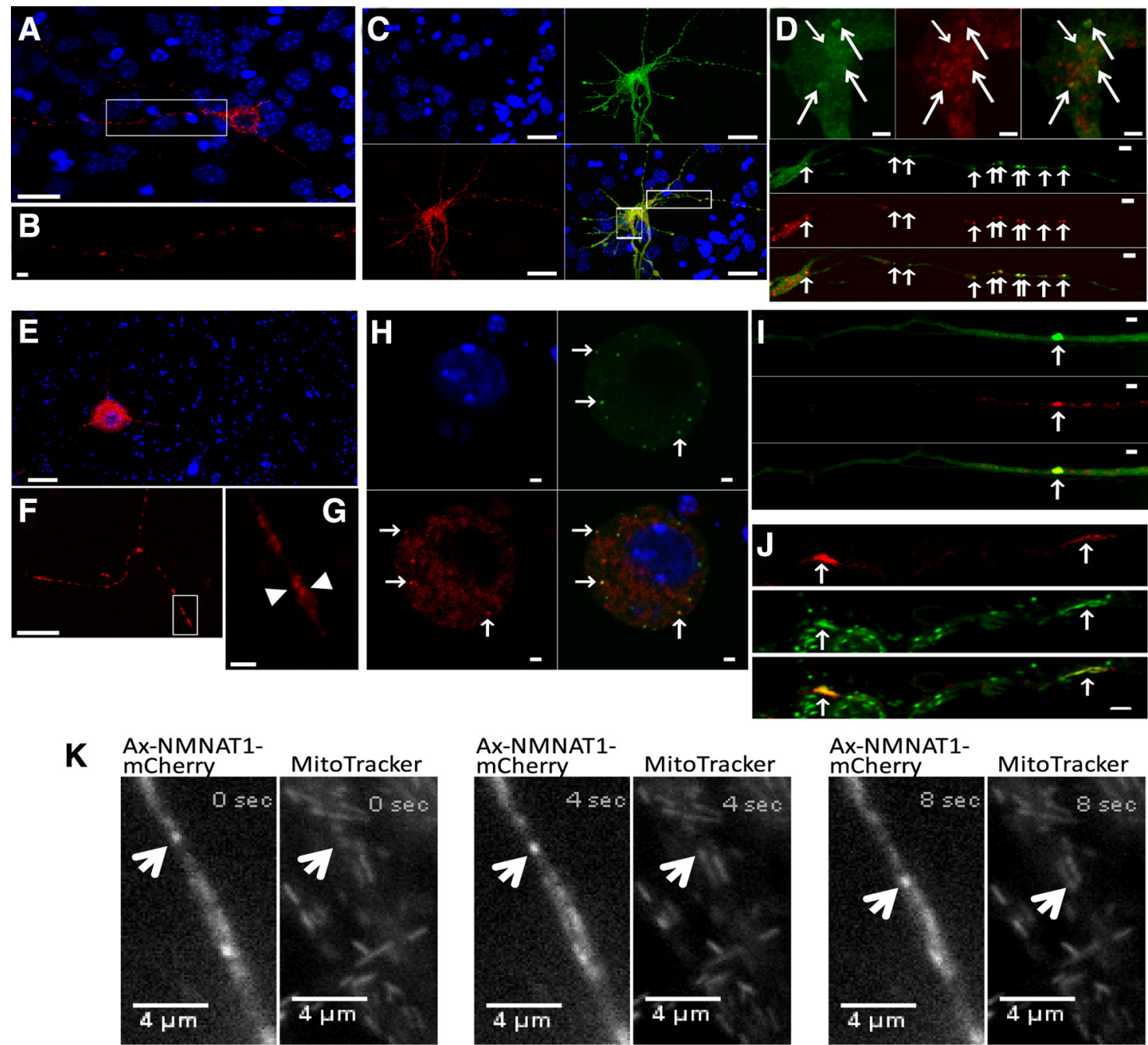

Ax-NMNAT1-

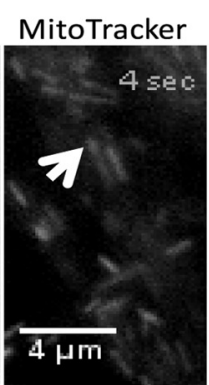

Ax-NMNAT1-

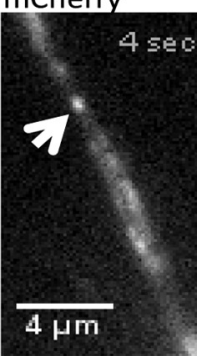

mCherry

MitoTracker
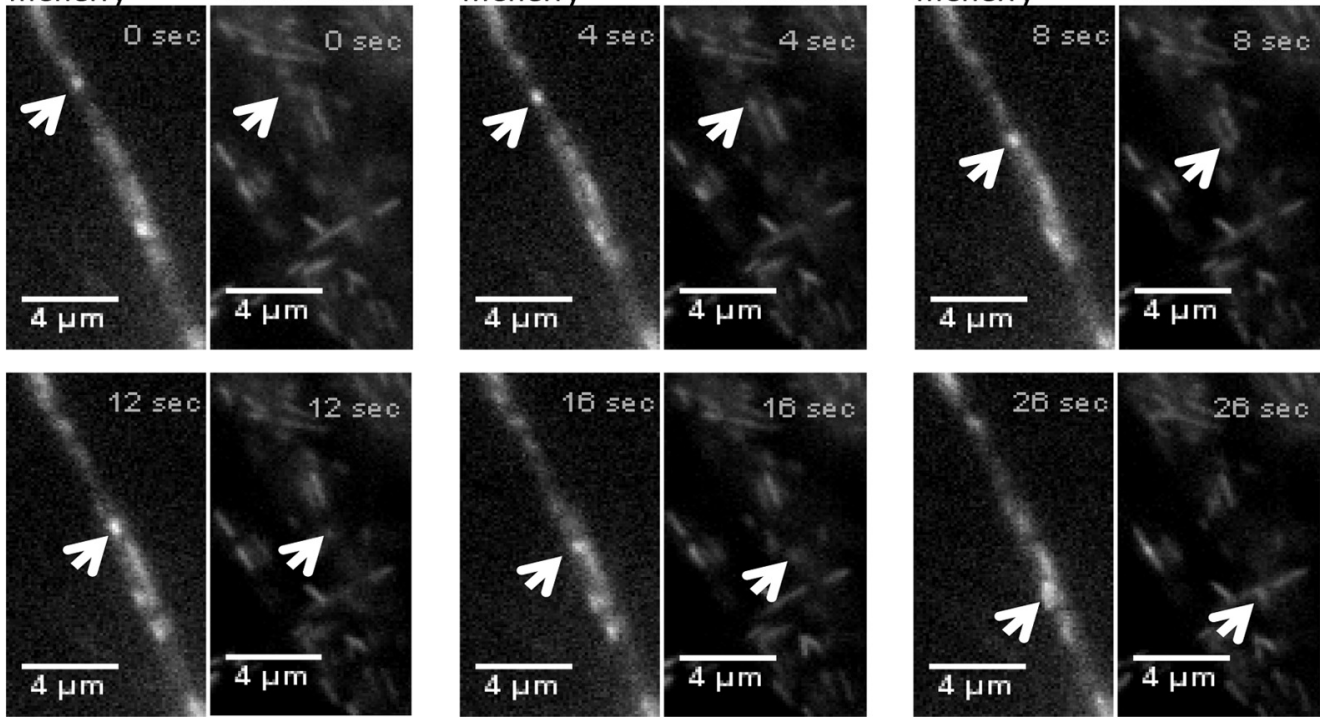

Figure 9. Localization of Ax-NMNAT1 protein in transfected primary cultures. $A$, Confocal z-projection of the subcellular distribution of Ax-NMNAT1-mCherry in transfected hippocampal neuron. $B$, Single confocal plane of the axonal inset in $\boldsymbol{A}$. C, Confocal z-projection of Ax-NMNAT1-mCherry and $\Delta$ NLS WId ${ }^{5}$-EGFP cotransfected hippocampal neuron. D, Single confocal plane of the soma and axon insets in $\boldsymbol{C} . \boldsymbol{E}, \boldsymbol{F}$, Confocal z-projection of the subcellular distribution of Ax-NMNAT1-mCherry in transfected DRG and its growth cone respectively. $\boldsymbol{G}$, Single confocal plane of the inset in $\boldsymbol{F}$; arrowheads point to Ax-NMNAT1-mCherry puncta at the growth cone. $\boldsymbol{H}$, I, Single confocal plane of soma and axon, respectively, of an Ax-NMNAT1-mCherry and $\triangle N$ NLS WId ${ }^{S}$-EGFP cotransfected DRG. In $\boldsymbol{D}, \boldsymbol{H}$, and $\boldsymbol{I}$, arrows indicate partial colocalization of Ax-NMNAT1 with $\Delta$ NLS WId ${ }^{S}$. Scale bars: $\boldsymbol{A}, \boldsymbol{C}, \boldsymbol{E}, \boldsymbol{F}, 20 \mu \mathrm{m} ; \boldsymbol{B}, \boldsymbol{D}, \boldsymbol{G}-\boldsymbol{I}, 2 \mu \mathrm{m}$. In $\boldsymbol{A}-\boldsymbol{I}$, blue is DAPI staining, red is Ax-NMNAT1-mCherry fluorescence, and green is $\triangle$ NLS WId ${ }^{S}$-EGFP fluorescence. J, Single confocal plane showing colocalization (arrows) of Ax-NMNAT1-mCherry particles and mitochondria (MitoTracker Green) in a transfected DRG axon. Scale bar, $2 \mu \mathrm{m}$. $\boldsymbol{K}$, Time-lapse imaging of the experiment in $\boldsymbol{J}$, showing coordinated retrograde movement of an Ax-NMNAT1-mCherry particle (arrow, left) with a mitochondrion (arrow, right). Images were zoomed from supplemental Movie 1 (available at www.jneurosci.org as supplemental material).

port block is delayed if Ax-NMNAT1 has been delivered to axons before the damage occurred. This could explain the great protection Wld ${ }^{\mathrm{S}}$ exerted in the pmn model (Ferri et al., 2003). Thus, enhanced targeting of Wld ${ }^{S}$ or NMNAT1 locally may help preserving synapses and counteract damage caused by axonal transport blockage.

Axonal Wld ${ }^{\mathrm{S}}$ can be detected in the form of granular staining in vivo and in multisize particles in vitro. We show that Ax-NMNAT1 and extranuclear Wld ${ }^{\mathrm{S}}$ share a common subcellular location in small membranous compartments, in particular subcellular fractions enriched in mitochondria, Golgi, and synaptic vesicles. In this context, we show for the first time coordinated movement of Ax-NMNAT1 with mitochondria in axons, in line with the previously demonstrated association between $\Delta$ NLS Wld ${ }^{\mathrm{S}}$ and mitochondria (Beirowski et al., 2009).

In view of the employed axonal targeting motif, the mitochondrial association seems surprising. The targeting sequence is part of the C-terminal cytoplasmic domain of APP, which, after cleavage 
from the full-length APP, is sorted to the axon in carrier vesicles (Muresan et al., 2009). The NPTY motif contained in the axonal targeting peptide is involved in the trafficking of synaptic vesicles. In Drosophila, it mediates axonal accumulation of synaptic markers upon APP overexpression (Rusu et al., 2007). Although APP interacts with a vast number of proteins, the 15 aa peptide we used is only likely to interact with Mint/X11, via the NPTY domain (Russo et al., 1998). Mint/X11 are adaptors containing distinct domains for binding various proteins, one of which is the synaptic vesicle fusion protein Munc18-1 (Okamoto and Südhof, 1997). Mint deletion produces presynaptic functional deficit in $\mathrm{KO}$ mice (Ho et al., 2006), whereas overexpression ameliorates long-term potentiation deficits in Alzheimer's disease mouse models (Mitchell et al., 2009).

Ax-NMNAT1 and Wld ${ }^{\mathrm{S}}$ are abundant in brain subcellular fractions enriched for Golgi apparatus and ER. Perhaps not coincidentally, a strikingly similar distribution has been observed in neurons transfected with neurexin, another protein interacting with Mint1. The exit of neurexin from the ER/Golgi and its trafficking to synapses in vesicles depends on its C-terminal sequence, where the domain for interaction with Mintl resides (Fairless et al., 2008). Although a direct interaction between APP and kinesin is controversial (Kamal et al., 2001; Lazarov et al., 2005), the exit of vesicles containing APP from the trans-Golgi-network is mediated by calsyntenin-1 (Ludwig et al., 2009). Calsyntenin-1 is a neuronal transmembrane protein transported to axons in vesicular carriers in a kinesin 1-dependent manner (Konecna et al., 2006; Ludwig et al., 2009). Strikingly, by using the same subcellular fraction method that we use in the present study, Ludwig et al. (2009) showed that calsyntenin- 1 concentrates in the subcellular vesicle fractions V0 and $\mathrm{V} 1$, where we found Ax-NMNAT1 and Wld ${ }^{\mathrm{S}}$ mostly present. Although we show that Ax-NMNAT1 does not colocalize with calsyntenin-1, and $\mathrm{p} 38 \mathrm{SNPH}$, we cannot exclude a possible colocalization with other vesicles of similar size. In fact, Ax-NMNAT1mCherry fluorescence was not confined to mitochondria. In this context, it is interesting to note evidence for physical connection between ER and mitochondria (de Brito and Scorrano, 2008).

Since the C-terminal fragment of APP is not reported to be targeted to mitochondria (Devi and Anandatheerthavarada, 2010), it is possible that the striking mitochondria localization of Ax-NMNAT1 is determined by NMNAT 1 itself. When ectopically present in axons NMNAT1 may dynamically associate with mitochondria. Accordingly, we noticed a progressive increase in number of cytoplasmic particles of $\Delta$ NLS Wld ${ }^{\mathrm{S}}$-EGFP with time after transfection (data not shown). Because $\Delta$ NLS Wld ${ }^{\mathrm{S}}$ cytoplasmic puncta colocalize with mitochondria (Beirowski et al., 2009) their increase in number may underlie a progressive delivery of Wld ${ }^{\mathrm{S}}$ and NMNAT1 to these organelles after transfection. A mitochondrial involvement in the mechanism of Wld ${ }^{\mathrm{S}}$ and NMNAT1 protection would be in line with recent findings showing that mitochondrial NMNAT3 protects in vivo (Yahata et al., 2009). Further targeting studies may help to resolve whether Wld ${ }^{\mathrm{S}}$, NMNAT1, and other axon-protective molecules mechanistically act at a specific axonal location and whether this coincides with mitochondria.

In summary, our data provide the first evidence that NMNAT1 transport to axons and synapses is indispensable for protection. The unprotective nuclear NMNAT1 protein was transformed into a strong inhibitor of Wallerian degeneration by specific targeting to axons. We shed light on possible axonal sites of action facilitating future analysis of the molecular mechanism. Importantly, this could be therapeutically exploited, especially in disorders where synapse loss is a limiting factor, and the local mechanism of protection could pave the way for direct intervention in the distal stump of a nerve after injury.

\section{References}

Araki T, Sasaki Y, Milbrandt J (2004) Increased nuclear NAD biosynthesis and SIRT1 activation prevent axonal degeneration. Science 305:1010-1013.

Avery MA, Sheehan AE, Kerr KS, Wang J, Freeman MR (2009) Wld S requires Nmnatl enzymatic activity and N16-VCP interactions to suppress Wallerian degeneration. J Cell Biol 184:501-513.

Beirowski B, Berek L, Adalbert R, Wagner D, Grumme DS, Addicks K, Ribchester RR, Coleman MP (2004) Quantitative and qualitative analysis of Wallerian degeneration using restricted axonal labelling in YFP-H mice. J Neurosci Methods 134:23-35.

Beirowski B, Adalbert R, Wagner D, Grumme DS, Addicks K, Ribchester RR, Coleman MP (2005) The progressive nature of Wallerian degeneration in wild-type and slow Wallerian degeneration (WldS) nerves. BMC Neurosci 6:6.

Beirowski B, Babetto E, Coleman MP, Martin KR (2008) The WldS gene delays axonal but not somatic degeneration in a rat glaucoma model. Eur J Neurosci 28:1166-1179.

Beirowski B, Babetto E, Gilley J, Mazzola F, Conforti L, Janeckova L, Magni G, Ribchester RR, Coleman MP (2009) Non-nuclear Wld(S) determines its neuroprotective efficacy for axons and synapses in vivo. J Neurosci 29:653-668.

Berger F, Lau C, Dahlmann M, Ziegler M (2005) Subcellular compartmentation and differential catalytic properties of the three human nicotinamide mononucleotide adenylyltransferase isoforms. J Biol Chem 280:36334-36341.

Brunetti M, Miscena A, Salviati A, Gaiti A (1987) Effect of aging on the rate of axonal transport of choline-phosphoglycerides. Neurochem Res 12:61-65.

Cavalli V, Kujala P, Klumperman J, Goldstein LS (2005) Sunday Driver links axonal transport to damage signaling. J Cell Biol 168:775-787.

Cheng HC, Burke RE (2010) The Wld(S) mutation delays anterograde, but not retrograde, axonal degeneration of the dopaminergic nigro-striatal pathway in vivo. J Neurochem 113:683-691.

Coleman M (2005) Axon degeneration mechanisms: commonality amid diversity. Nat Rev Neurosci 6:889-898.

Conforti L, Tarlton A, Mack TG, Mi W, Buckmaster EA, Wagner D, Perry VH, Coleman MP (2000) A Ufd2/D4Colele chimeric protein and overexpression of Rbp7 in the slow Wallerian degeneration (WldS) mouse. Proc Natl Acad Sci U S A 97:11377-11382.

Conforti L, Fang G, Beirowski B, Wang MS, Sorci L, Asress S, Adalbert R, Silva A, Bridge K, Huang XP, Magni G, Glass JD, Coleman MP (2007) $\mathrm{NAD}(+)$ and axon degeneration revisited: Nmnatl cannot substitute for Wld(S) to delay Wallerian degeneration. Cell Death Differ 14:116-127.

Conforti L, Wilbrey A, Morreale G, Janeckova L, Beirowski B, Adalbert R, Mazzola F, Di Stefano M, Hartley R, Babetto E, Smith T, Gilley J, Billington RA, Genazzani AA, Ribchester RR, Magni G, Coleman M (2009) Wld $S$ protein requires Nmnat activity and a short $\mathrm{N}$-terminal sequence to protect axons in mice. J Cell Biol 184:491-500.

de Brito OM, Scorrano L (2008) Mitofusin 2 tethers endoplasmic reticulum to mitochondria. Nature 456:605-610.

Devi L, Anandatheerthavarada HK (2010) Mitochondrial trafficking of APP and alpha synuclein: relevance to mitochondrial dysfunction in Alzheimer's and Parkinson's diseases. Biochim Biophys Acta 1802:11-19.

Fairless R, Masius H, Rohlmann A, Heupel K, Ahmad M, Reissner C, Dresbach T, Missler M (2008) Polarized targeting of neurexins to synapses is regulated by their C-terminal sequences. J Neurosci 28:12969-12981.

Fang C, Bernardes-Silva M, Coleman MP, Perry VH (2005) The cellular distribution of the Wld $\mathrm{s}$ chimeric protein and its constituent proteins in the CNS. Neuroscience 135:1107-1118.

Feng G, Mellor RH, Bernstein M, Keller-Peck C, Nguyen QT, Wallace M, Nerbonne JM, Lichtman JW, Sanes JR (2000) Imaging neuronal subsets in transgenic mice expressing multiple spectral variants of GFP. Neuron 28:41-51.

Ferri A, Sanes JR, Coleman MP, Cunningham JM, Kato AC (2003) Inhibiting axon degeneration and synapse loss attenuates apoptosis and disease progression in a mouse model of motoneuron disease. Curr Biol 13:669-673.

Fischer LR, Culver DG, Davis AA, Tennant P, Wang M, Coleman M, Asress S, Adalbert R, Alexander GM, Glass JD (2005) The WldS gene modestly prolongs survival in the SOD1G93A fALS mouse. Neurobiol Dis 19: 293-300. 
Gilley J, Coleman MP (2010) Endogenous Nmnat2 is an essential survival factor for maintenance of healthy axons. PLoS Biol 8:e1000300.

Gillingwater TH, Thomson D, Mack TG, Soffin EM, Mattison RJ, Coleman MP, Ribchester RR (2002) Age-dependent synapse withdrawal at axotomised neuromuscular junctions in Wld(s) mutant and Ube4b/Nmnat transgenic mice. J Physiol 543:739-755.

Ho A, Morishita W, Atasoy D, Liu X, Tabuchi K, Hammer RE, Malenka RC, Südhof TC (2006) Genetic analysis of Mint/X11 proteins: essential presynaptic functions of a neuronal adaptor protein family. J Neurosci 26:13089-13101.

Howell GR, Libby RT, Jakobs TC, Smith RS, Phalan FC, Barter JW, Barbay JM, Marchant JK, Mahesh N, Porciatti V, Whitmore AV, Masland RH, John SW (2007) Axons of retinal ganglion cells are insulted in the optic nerve early in DBA/2J glaucoma. J Cell Biol 179:1523-1537.

Jia H, Yan T, Feng Y, Zeng C, Shi X, Zhai Q (2007) Identification of a critical site in Wld(s): essential for Nmnat enzyme activity and axon-protective function. Neurosci Lett 413:46-51.

Kamal A, Almenar-Queralt A, LeBlanc JF, Roberts EA, Goldstein LS (2001) Kinesin-mediated axonal transport of a membrane compartment containing beta-secretase and presenilin-1 requires APP. Nature 414: 643-648.

Kang JS, Tian JH, Pan PY, Zald P, Li C, Deng C, Sheng ZH (2008) Docking of axonal mitochondria by syntaphilin controls their mobility and affects short-term facilitation. Cell 132:137-148.

Konecna A, Frischknecht R, Kinter J, Ludwig A, Steuble M, Meskenaite V, Indermühle $\mathrm{M}$, Engel $\mathrm{M}$, Cen $\mathrm{C}$, Mateos JM, Streit $\mathrm{P}$, Sonderegger $\mathrm{P}$ (2006) Calsyntenin-1 docks vesicular cargo to kinesin-1. Mol Biol Cell 17:3651-3663.

Kordeli E, Lambert S, Bennett V (1995) AnkyrinG. A new ankyrin gene with neural-specific isoforms localized at the axonal initial segment and node of Ranvier. J Biol Chem 270:2352-2359.

Lazarov O, Morfini GA, Lee EB, Farah MH, Szodorai A, DeBoer SR, Koliatsos VE, Kins S, Lee VM, Wong PC, Price DL, Brady ST, Sisodia SS (2005) Axonal transport, amyloid precursor protein, kinesin-1, and the processing apparatus: revisited. J Neurosci 25:2386-2395.

Lubińska L (1977) Early course of Wallerian degeneration in myelinated fibres of the rat phrenic nerve. Brain Res 130:47-63.

Ludwig A, Blume J, Diep TM, Yuan J, Mateos JM, Leuthäuser K, Steuble M, Streit P, Sonderegger P (2009) Calsyntenins mediate TGN exit of APP in a kinesin-1-dependent manner. Traffic 10:572-589.

Lunn ER, Perry VH, Brown MC, Rosen H, Gordon S (1989) Absence of Wallerian degeneration does not hinder regeneration in peripheral nerve. Eur J Neurosci 1:27-33.

Mack TG, Reiner M, Beirowski B, Mi W, Emanuelli M, Wagner D, Thomson D, Gillingwater T, Court F, Conforti L, Fernando FS, Tarlton A, Andressen C, Addicks K, Magni G, Ribchester RR, Perry VH, Coleman MP (2001) Wallerian degeneration of injured axons and synapses is delayed by a Ube4b/Nmnat chimeric gene. Nat Neurosci 4:1199-1206.

Mi W, Beirowski B, Gillingwater TH, Adalbert R, Wagner D, Grumme D, Osaka H, Conforti L, Arnhold S, Addicks K, Wada K, Ribchester RR, Coleman MP (2005) The slow Wallerian degeneration gene, WldS, inhibits axonal spheroids pathology in gracile axonal dystrophy mice. Brain 128:405-416.

Mitchell JC, Ariff BB, Yates DM, Lau KF, Perkinton MS, Rogelj B, Stephenson JD, Miller CC, McLoughlin DM (2009) X11\{beta\} rescues memory and long-term potentiation deficits in Alzheimer's disease APPswe Tg2576 mice. Hum Mol Genet 18:4492-4500.

Morfini G, Tsai MY, Szebenyi G, Brady ST (2001) Approaches to study interactions between kinesin motors and membranes. Methods Mol Biol 164:147-162.

Muresan V, Varvel NH, Lamb BT, Muresan Z (2009) The cleavage products of amyloid- $\beta$ precursor protein are sorted to distinct carrier vesicles that are independently transported within neurites. J Neurosci 29:3565-3578.

Okamoto M, Südhof TC (1997) Mints, Munc18-interacting proteins in synaptic vesicle exocytosis. J Biol Chem 272:31459-31464.

Raff MC, Whitmore AV, Finn JT (2002) Axonal self-destruction and neurodegeneration. Science 296:868-871.

Ribchester RR, Mao F, Betz WJ (1994) Optical measurements of activitydependent membrane recycling in motor nerve terminals of mammalian skeletal muscle. Proc Biol Sci 255:61-66.
Rivera JF, Ahmad S, Quick MW, Liman ER, Arnold DB (2003) An evolutionarily conserved dileucine motif in Shal $\mathrm{K}+$ channels mediates dendritic targeting. Nat Neurosci 6:243-250.

Russo T, Faraonio R, Minopoli G, De Candia P, De Renzis S, Zambrano N (1998) Fe65 and the protein network centered around the cytosolic domain of the Alzheimer's beta-amyloid precursor protein. FEBS Lett 434:1-7.

Rusu P, Jansen A, Soba P, Kirsch J, Löwer A, Merdes G, Kuan YH, Jung A, Beyreuther K, Kjaerulff O, Kins S (2007) Axonal accumulation of synaptic markers in APP transgenic Drosophila depends on the NPTY motif and is paralleled by defects in synaptic plasticity. Eur J Neurosci 25:1079-1086

Sajadi A, Schneider BL, Aebischer P (2004) Wlds-mediated protection of dopaminergic fibers in an animal model of Parkinson disease. Curr Biol 14:326-330.

Samsam M, Mi W, Wessig C, Zielasek J, Toyka KV, Coleman MP, Martini R (2003) The $W l d^{s}$ mutation delays robust loss of motor and sensory axons in a genetic model for myelin-related axonopathy. J Neurosci 23: 2833-2839.

Sasaki Y, Vohra BP, Lund FE, Milbrandt J (2009a) Nicotinamide mononucleotide adenylyl transferase-mediated axonal protection requires enzymatic activity but not increased levels of neuronal nicotinamide adenine dinucleotide. J Neurosci 29:5525-5535.

Sasaki Y, Vohra BP, Baloh RH, Milbrandt J (2009b) Transgenic mice expressing the Nmnat 1 protein manifest robust delay in axonal degeneration in vivo. J Neurosci 29:6526-6534.

Satpute-Krishnan P, DeGiorgis JA, Conley MP, Jang M, Bearer EL (2006) A peptide zipcode sufficient for anterograde transport within amyloid precursor protein. Proc Natl Acad Sci U S A 103:16532-16537.

Saxena S, Caroni P (2007) Mechanisms of axon degeneration: from development to disease. Prog Neurobiol 83:174-191.

Schweiger M, Hennig K, Lerner F, Niere M, Hirsch-Kauffmann M, Specht T, Weise C, Oei SL, Ziegler M (2001) Characterization of recombinant human nicotinamide mononucleotide adenylyl transferase (NMNAT), a nuclear enzyme essential for NAD synthesis. FEBS Lett 492:95-100.

Takenaka T, Kawakami T, Hikawa N, Gotoh H (1990) Axoplasmic transport of mitochondria in cultured dorsal root ganglion cells. Brain Res 528:285-290.

Waller A (1850) Experiments on the section of glossopharyngeal and hypoglossal nerves of the frog and observations of the alterations produced thereby in the structure of their primitive fibres. Philos Trans R Soc Lond B Biol Sci 140:423-429.

Watanabe Y, Yasui K, Nakano T, Doi K, Fukada Y, Kitayama M, Ishimoto M, Kurihara S, Kawashima M, Fukuda H, Adachi Y, Inoue T, Nakashima K (2005) Mouse motor neuron disease caused by truncated SOD1 with or without C-terminal modification. Brain Res Mol Brain Res 135:12-20.

Wilbrey AL, Haley JE, Wishart TM, Conforti L, Morreale G, Beirowski B, Babetto E, Adalbert R, Gillingwater TH, Smith T, Wyllie DJ, Ribchester RR, Coleman MP (2008) VCP binding influences intracellular distribution of the slow Wallerian degeneration protein, Wld(S). Mol Cell Neurosci 38:325-340.

Wong F, Fan L, Wells S, Hartley R, Mackenzie FE, Oyebode O, Brown R, Thomson D, Coleman MP, Blanco G, Ribchester RR (2009) Axonal and neuromuscular synaptic phenotypes in Wld(S), SOD1(G93A) and ostes mutant mice identified by fiber-optic confocal microendoscopy. Mol Cell Neurosci 42:296-307.

Yahata N, Yuasa S, Araki T (2009) Nicotinamide mononucleotide adenylyltransferase expression in mitochondrial matrix delays Wallerian degeneration. J Neurosci 29:6276-6284.

Zhai RG, Cao Y, Hiesinger PR, Zhou Y, Mehta SQ, Schulze KL, Verstreken P, Bellen HJ (2006) Drosophila NMNAT maintains neural integrity independent of its NAD synthesis activity. PLoS Biol 4:e416.

Zhang HL, Pan F, Hong D, Shenoy SM, Singer RH, Bassell GJ (2003) Active transport of the survival motor neuron protein and the role of exon-7 in cytoplasmic localization. J Neurosci 23:6627-6637.

Zuber MX, Strittmatter SM, Fishman MC (1989) A membrane-targeting signal in the $\mathrm{N}$ terminus of the neuronal protein GAP-43. Nature 341: 345-348. 